\title{
NAD1 Controls Defense-Like Responses in Medicago truncatula Symbiotic Nitrogen Fixing Nodules Following Rhizobial Colonization in a BacA-Independent Manner
}

\author{
Ágota Domonkos ${ }^{1}$, Szilárd Kovács ${ }^{2,3}$, Anikó Gombár ${ }^{1}$, Ernő Kiss ${ }^{3}$, Beatrix Horváth ${ }^{1}$, \\ Gyöngyi Z. Kováts ${ }^{1}$, Attila Farkas ${ }^{2}$, Mónika T. Tóth ${ }^{1}$, Ferhan Ayaydin ${ }^{4}$, Károly Bóka ${ }^{5}$, \\ Lili Fodor ${ }^{1}$, Pascal Ratet ${ }^{6,7}$ (D), Attila Kereszt ${ }^{2}$ (D), Gabriella Endre ${ }^{2,3}$ and Péter Kaló ${ }^{1, *}$ \\ 1 National Agricultural and Innovation Center, Agricultural Biotechnology Institute, 2100 Gödöllő, Hungary; \\ domonkos.agota@abc.naik.hu (A.D.); gombar.aniko@abc.naik.hu (A.G.); horvath.beatrix@abc.naik.hu (B.H.); \\ kovats.gyongyi@abc.naik.hu (G.Z.K.); toth.monika.tunde@abc.naik.hu (M.T.T.); fodor.lili@abc.naik.hu (L.F.); \\ kalo.peter@abc.naik.hu (P.K.) \\ 2 Institute of Plant Biology, Biological Research Center, 6726 Szeged, Hungary; \\ kovacs.szilard@brc.mta.hu (S.K.); farkasa8@gmail.com (A.F.); kereszta@gmail.com (A.K.); \\ endre.gabriella@brc.mta.hu (G.E.) \\ 3 Institute of Genetics, Biological Research Center, 6726 Szeged, Hungary; kiss.erno@brc.mta.hu \\ 4 Cellular Imaging Laboratory, Biological Research Center, 6726 Szeged, Hungary; aferhan@gmail.com \\ 5 Department of Plant Anatomy, Eötvös Loránd University, 1117 Budapest, Hungary; \\ karolyboka@caesar.elte.hu \\ 6 Institute of Plant Sciences Paris-Saclay IPS2, CNRS, INRA, Université Paris-Sud, Université Evry, \\ Université Paris-Saclay, Bâtiment 630, 91405 Orsay, France; pascal.ratet@ips2.universite-paris-saclay.fr \\ 7 Institute of Plant Sciences Paris-Saclay IPS2, Paris Diderot, Sorbonne Paris-Cité, Bâtiment 630, \\ 91405 Orsay, France \\ * Correspondence: kalo.peter@abc.naik.hu; Tel.: +36-28-526-104
}

Received: 31 October 2017; Accepted: 11 December 2017; Published: 14 December 2017

\begin{abstract}
Legumes form endosymbiotic interaction with host compatible rhizobia, resulting in the development of nitrogen-fixing root nodules. Within symbiotic nodules, rhizobia are intracellularly accommodated in plant-derived membrane compartments, termed symbiosomes. In mature nodule, the massively colonized cells tolerate the existence of rhizobia without manifestation of visible defense responses, indicating the suppression of plant immunity in the nodule in the favur of the symbiotic partner. Medicago truncatula DNF2 (defective in nitrogen fixation 2) and NAD1 (nodules with activated defense 1) genes are essential for the control of plant defense during the colonization of the nitrogen-fixing nodule and are required for bacteroid persistence. The previously identified nodule-specific NAD1 gene encodes a protein of unknown function. Herein, we present the analysis of novel NAD1 mutant alleles to better understand the function of NAD1 in the repression of immune responses in symbiotic nodules. By exploiting the advantage of plant double and rhizobial mutants defective in establishing nitrogen-fixing symbiotic interaction, we show that NAD1 functions following the release of rhizobia from the infection threads and colonization of nodule cells. The suppression of plant defense is self-dependent of the differentiation status of the rhizobia. The corresponding phenotype of nad1 and dnf2 mutants and the similarity in the induction of defense-associated genes in both mutants suggest that NAD1 and DNF2 operate close together in the same pathway controlling defense responses in symbiotic nodules.
\end{abstract}

Keywords: defense response; nodule; symbiosis; nitrogen fixation; legume; Medicago truncatula; rhizobia 


\section{Introduction}

Medicago truncatula and other leguminous plants are able to establish nitrogen-fixing symbiotic associations with soil bacteria that are belonging to the genus rhizobia. The symbiotic interaction between the rhizobia and the host plant is initiated by exchange of chemical signals between the two partners resulting in the formation the root nodules, wherein nitrogen fixation takes place $[1,2]$. Plant flavonoids secreted into the rhizosphere induce the production of the bacterial signal molecule, the nodulation factor (NF) that triggers morphological changes, root hair curling and cortical cell division, and physiological responses, such as ion fluxes, calcium oscillations, and transcriptional activation of symbiosis associated genes [1], in the host plant. Rhizobia are required for the initiation and growth of infection threads (ITs) that develop towards the newly formed nodule primordia by penetrating the outer cortical cell layers [3].

When ITs reach nodule primordia, bacteria are released from these ITs and colonize the host cells through endocytosis. The bacteria are accommodated in a cytoplasmic structure referred to as the symbiosome that is delimited by a plant derived peribacteroid membrane.

The symbiotic interaction between Sinorhizobium (Ensifer) sp. and M. truncatula leads to the formation of cylindrical-shaped indeterminate nodules that possess a persistent meristem. The mature indeterminate nodules are composed of histological zones containing nodule cells and rhizobia at different developmental states [4]. The continuously active meristem (zone I, ZI) produces cells, which internalize rhizobia in the infection zone (ZII), both colonized host cells, and rhizobia differentiate in interzone (IZ), differentiated bacteroids reduce nitrogen to ammonium in zone III, and plant cell content and bacteroids are being degraded in the senescence zone (ZIV) proximal to the root tissue. In indeterminate nodules, bacteria undergo irreversible morphological changes (shape alteration, enlargement, and polyploidization) [5]. This terminal differentiation is governed by nodule-specific cysteine-rich antimicrobial peptides (NCRs), which are produced in infected host cells [6], and are targeted to symbiosomes. This process requires the M. truncatula DNF1 protein, a nodule-specific subunit of a signal peptidase [7]. The bacterial BacA protein is required for Sinorhizobium meliloti differentiation and chronic infection of $M$. truncatula nodules. S. meliloti strain deficient in BacA is susceptible for the antimicrobial effect of NCRs and rhizobia are rapidly killed once they are released from ITs [8].

During the infection process and internalization of rhizobia in the host cells, bacteria invade plant tissues without provoking chronic defense responses, indicating the control of plant immunity in nodules during the symbiotic process. For instance, transcriptome studies revealed the induction of defense-associated genes in legumes few hours post inoculation with compatible rhizobia, and this activation was attenuated hours later [9-11]. The generation of reactive oxygen species (ROS) is an important component of plant defense [12]. The abortion of infection threads, the outcome of the autoinhibition process to control the number of infection events is coupled with presence of polyphenolics, and is accompanied with hypersensitive reaction, showing a role for plant defense responses during infection [13]. The control of hydrogen peroxide level is required for the fine tuning of the infection process [14], but ROS act as signaling molecules during the rhizobial invasion and moreover regulate nodule senescence [15]. S. meliloti exoY mutant, defective in succinoglycan (exopolysaccharide I; EPS-I) production, induces the formation of root hair curling, but is deficient in infection thread formation [16]. M. truncatula plants that are inoculated with the succinoglycan-deficient $S$. meliloti show the induction of plant defense responses [17] and strong activation of defense-related genes in M. truncatula roots [16], suggesting a function for EPS in suppression of defense-responses during the infection process.

The suppression of plant immunity is required not only during the early infection events but later as well since nodule cells have to tolerate the massive colonization of rhizobia during the establishment and maintenance of the nitrogen-fixing rhizobium-legume symbiosis [18]. M. truncatula mutants that are deficient in the DNF2 (Defective in Nitrogen Fixation 2), SymCRK (Symbiotic Cysteine-rich Receptor-like Kinase), NAD1 (Nodules with Activated Defense 1) and RSD (Regulator of Symbiosome Differentiation) 
genes display strong defense-related responses, indicating the loss of control over suppression of plant immunity [19-22]. DNF2 and SymCRK encode a phospholipase-like protein and cysteine-rich receptor-like kinase with a non-arginine-aspartate motif, respectively, whereas, RSD encodes a $\mathrm{C}_{2} \mathrm{H}_{2}$ transcription factor. Their functions have not been clearly determined in repressing plant defense response, but a recent model has proposed the successive operation of DNF2, SymCRK, and RSD to regulate rhizobial colonization and persistence in M. truncatula nodules [23].

Finally, the nad1 mutant showed severe necrotic phenotype with low bacterial occupancy of the nodules, indicating the requirement of NAD1 in the maintenance of nitrogen fixing endosymbiosis [21]. The nodule specific $M$. truncatula NAD1 encodes a protein with unknown function and its homologs are specifically present in plants establishing root nodule symbiosis.

Here, we report the phenotypic analysis and the functional study of additional mutant alleles of NAD1. To better understand the function of NAD1 in suppression of plant immunity during nodule differentiation, the transcriptional analysis of defense-associated genes and the accumulation of phenolic compounds were monitored in single and double M. truncatula symbiotic mutants, defective in establishing effective nitrogen-fixing interaction, inoculated with wild-type and symbiotic mutant rhizobia.

\section{Materials and Methods}

\subsection{Plant Material, Growth Condition and Bacterial Strains}

Medicago truncatula Jemalong, A20 and 2HA genotypes were used as wild-type controls in phenotypic characterization and genetic mapping experiments. dnf1-1, dnf2-1, lin-2, ipd3-1, 7Y (nad1-3), N5896 (nad1-4) mutants listed in Supplementary Table S1A were used for phenotypic characterization, expression analyses, and generating double symbiotic mutants. Seeds were chemically scarified with sulfuric acid and sterilized, as described in the M. truncatula handbook [24]. Seeds were germinated with overnight incubation in dark at room temperature on inverted agar plates (1.0\% water-agar) following 4-6 days-long cold treatment at $4{ }^{\circ} \mathrm{C}$. All of the seedlings were grown in zeolite substrate (Geoproduct Kft., Mád, Hungary) for five days before inoculation with rhizobia. Genetic crossings between symbiotic mutants and genotypes were carried out according to the method described by [24]. Double mutants were confirmed by polymerase chain reaction (PCR) amplification or sequencing the PCR products (lin-2) of the mutant genes using the oligonucleotide primers listed in Supplementary Table S2.

Plants were infected with rhizobial strains Sinorhizobium (Ensifer) meliloti 1021, Sinorhizobium (Ensifer) medicae WSM419 carrying the pXLGD4 plasmid, expressing the lacZ reporter gene under the control of the hemA promoter or S. medicae WSM419 containing the pMEpTrpGFPGUS plasmid, expressing the $\beta$-glucoronidase gene and the green fluorescent protein (Supplementary Table S1B). The pMEpTrpGFPGUS plasmid [25] was transferred into $S$. mediace by triparental mating [26]. The S. meliloti 1021 nodA mutant was created by phage transduction. The mutated nodA gene carrying a Tn5 insertion was transduced from the S. meliloti 2011 nodA mutant strain (GMI5382) [27] to S. meliloti 1021 background using the N3 bacteriophage [28]. The exoY and bacA mutant derivatives [16,29] of S. meliloti strain 1021 are listed in Supplementary Table S1B. Rhizobial strains were grown in Tryptone Yeast (TY) medium that was supplemented with $6 \mathrm{mM} \mathrm{CaCl}_{2}$ [30] and with the appropriate antibiotics for $24-48 \mathrm{~h}$ at $30{ }^{\circ} \mathrm{C}$, and inoculations were carried out as described by [30,31]. In hairy root transformation experiments and transient gene expression studies, Agrobacterium rhizogenes ARqua1 strain and Agrobacterium tumefaciens strain C58C1 were used.

\subsection{DNA Isolation and Genetic Mapping}

For genetic mapping and co-segregation analysis, the individuals of the nad1-3 $\times$ A20 F2 segregating and nad1-4 $\times 2$ HA back-crossed populations were grown in zeolite substrate, inoculated with S. medicae strain WSM419 (pXLGD4). F2 plants were scored for symbiotic phenotype and showing 
the symptoms of nitrogen starvation (presence of brown pigmentation in nodules, reduced growth habit and yellowish leaves) at 14, 21 and 28 days post-inoculation (dpi). The genomic DNA from M. truncatula plants was isolated using the ZenoGene40 plant DNA purification kit (Zenon Bio, Szeged, Hungary). The map position of nad1-3 was identified by analyzing the genotypes of the mapping population for a genetic marker set of the M. truncatula genome [32,33].

\subsection{Microscopy Analyses}

For microscopy analyses, harvested nodules were fixed in $4 \%$ paraformaldehyde solution in phosphate buffered saline (PBS) ( $\mathrm{pH}$ 7.4) [34] under vacuum for $3 \times 30 \mathrm{~s}$, and then kept at room temperature (RT) for $30 \mathrm{~min}$. The nodules were embedded in $5 \%$ agarose gel and $70 \mu \mathrm{m}$ longitudinal sections were prepared using Leica VT1200S vibratome (Leica Biosystems GmbH, Nussloch, Germany).

For LacZ activity, sections were stained with $0.1 \%$ XGal in PBS (pH 7.4) supplemented with $5 \mathrm{mM}$ potassium ferricyanide and $5 \mathrm{mM}$ potassium ferrocyanide for $1 \mathrm{~h}$ at $37^{\circ} \mathrm{C}$. Accumulation of phenolic compounds was detected by staining nodule sections with $0.1 \%$ toluidine blue solution in PBS buffer for 1 to $2 \mathrm{~min}$ at RT, or with a slightly modified protocol of potassium permanganate/methylene blue staining [13]. Briefly, nodule sections were vacuum-infiltrated for $30 \mathrm{~min}$ and post-fixed for $60 \mathrm{~min}$ in $2.5 \%$ glutaraldehyde in PBS (pH 7.4). Subsequently, they were rinsed in PBS (pH 7.4) three times for $5 \mathrm{~min}$, followed by incubating in $0.04 \%$ aqueous solution of $\mathrm{KMnO}_{4}$ for $5 \mathrm{~min}$ and then rinsed in PBS (pH 7.4) for $5 \mathrm{~min}$. The last steps of staining included with the incubation in $0.01 \%$ aqueous solution of methylene blue for $2 \mathrm{~min}$, and then the nodule sections were cleared with $2.4 \%$ sodium hypochlorite for $5 \mathrm{~min}$, rinsed in PBS (pH 7.4) three times for $1 \mathrm{~min}$. For the detection of rhizobia expressing the $\beta$-glucuronidase gene, nodule sections were stained for $1 \mathrm{~h}$ at $37^{\circ} \mathrm{C}$ with $2 \mathrm{mM} \mathrm{X}$-Gluc (Duchefa Biochemie, Haarlem, The Netherlands) in PBS that was supplemented with $5 \mathrm{mM}$ potassium ferricyanide and $5 \mathrm{mM}$ potassium ferrocyanide.

The stained sections were observed by Olympus BX41M light microscope with $10 \times$ and $20 \times$ objectives and images were captured using an Olympus Camedia E-10 digital camera (Olympus Life Science Europa $\mathrm{GmbH}$, Hamburg, Germany). For promoter analysis, $80 \mu \mathrm{m}$ sections of nodules from transformed roots were stained with $1 \mathrm{mM}$ Magenta-gluc (Duchefa Biochemie) in PBS supplemented with $5 \mathrm{mM}$ potassium ferricyanide and $5 \mathrm{mM}$ potassium ferrocyanide under vacuum for $30 \mathrm{~min}$ and $37^{\circ} \mathrm{C}$ for $4-16 \mathrm{~h}$. After fixation with $1.5 \%$ glutaraldehyde (Sigma, St. Louis, MO, USA), sections were washed and stained for LacZ activity as described above.

The viability test of bacteria was carried out for $20 \mathrm{~min}$ at room temperature on non-pre-fixed fresh nodule sections using the LIVE/DEAD BacLight ${ }^{\mathrm{TM}}$ Viability kit (Life Technologies, Carlsbad, CA, USA) containing $5 \mu \mathrm{M}$ SYTO9 and $30 \mu \mathrm{M}$ propidium iodide (PI) in $50 \mathrm{mM}$ Tris (pH 7.0) buffer, as described in [8]. Following rinses in deionized water, the images of nodule sections were acquired with Olympus Fluoview FV1000 confocal laser scanning microscopy (Olympus Life Science Europa GmbH).

To analyze the bacteroid morphology, nodule occupancy by rhizobia and autofluorescence, nodule sections were stained in PBS ( $\mathrm{pH}$ 7.4) containing $5 \mu \mathrm{M}$ SYTO13 (Life Technologies) for $20 \mathrm{~min}$, rinsed with $1 \times$ PBS, and sections were imaged using the same settings of confocal laser scanning microscopy, as described before [35].

To follow the subcellular localization of NAD1 and subcellular protein markers, $N$. benthamiana epidermal cells were analyzed using a Leica confocal microscope equipped with Argon (488 nm laserline) and helium-neon (543 nm laserline) lasers (Leica Microsystems, Heidelberg, Germany). Green fluorescent protein (GFP) fluorescence was imaged using excitation at $488 \mathrm{~nm}$ and detection between 500-550 nm. Discosoma sp. red fluorescent protein (DsRed)/mCherry fluorescence was imaged using excitation at $543 \mathrm{~nm}$ and detection between $560-650 \mathrm{~nm}$.

\subsection{Transmission and Scanning Electron Microscopy Analysis of the nad1-3 Mutant}

For transmission electron microscopy (TEM), 18-day-old halved nodules fixed in $2.5 \%$ glutaraldehyde in $0.1 \mathrm{M}$ phosphate buffer ( $\mathrm{pH}$ 7.2) for $3 \mathrm{~h}$ were washed in a $0.1 \mathrm{M}$ phosphate buffer 
and were post-fixed for $2 \mathrm{~h}$ with 1\% osmium tetroxide dissolved in the same buffer. Samples were rinsed in the buffer and dehydrated in a graded ethanol series and propylene oxide and subsequently infiltrated with and embedded in Durcupan epoxy resin. Ultrathin sections $(70 \mathrm{~nm})$ were cut with a Reichert Jung Ultracut E ultramicrotome (Reichert-Jung Inc., Vienna, Austria) and stained with uranyl acetate $(6 \mathrm{~min})$ and lead citrate $(6 \mathrm{~min})$. Sections were viewed at $75 \mathrm{kV}$ using a Hitachi 7100 transmission electron microscope (Hitachi, Tokyo, Japan).

For scanning electron microscopy (SEM), 8-day-old nodules were fixed with $2.5 \%$ glutaraldehyde in cacodylate buffer $(0.05 \mathrm{M}, \mathrm{pH} 7.2)$ overnight. The next day, following $0.1 \%$ osmium tetroxide treatment $\left(1 \mathrm{~h}, 4{ }^{\circ} \mathrm{C}\right.$, dark) nodules were embedded in 5\% agarose gel for sectioning. The $80-100 \mu \mathrm{m}$ sections were dehydrated in a graded ethanol series and dried with $\mathrm{CO}_{2}$ in a critical point dryer, followed by $10 \mathrm{~nm}$ of gold coating, and observed by SEM (JEOL JSM-7100F/LV; JEOL Europe BV, Zaventem, Belgium) [36].

\subsection{Gene Expression Analysis}

For real-time reverse transcription quantitative polymerase chain reaction (RT-qPCR), nodules were harvested at different time points in liquid nitrogen, RNA was extracted with TRI Reagent (Sigma) and Direct-zol RNA MiniPrep Kit (Zymo Research, Irvine, CA, USA). RNA was treated on column with DNaseI according to the manufacturer's instructions. Total RNA was quantified using a spectrophotometer (Nanodrop-1000; NanoDrop Technologies, Wilmington, DE, USA) and checked for quality by gel electrophoresis. Complementary DNA (cDNA) was prepared from $1 \mu \mathrm{g}$ total RNA with SuperScript III First-Strand Synthesis System for RT-PCR (Life Technologies) using oligo-dT primers according to the manufacturer's instructions. Quantitative real time RT-PCR was performed using a LightCycler 96 (Roche, Basel, Switzerland) and qPCRBIO SyGreen Mix (PCR BIOSYSTEMS, London, UK), according to the manufacturer's protocol. Cycle threshold values were obtained and data were analyzed by the LightCycler 96 SW1.1 software (Roche). The relative expression levels were calculated by normalization against the expression of the PTB (Polypyrimidine Tract-Binding-like protein, Medtr3g090960) and the ubiquitin-like gene (Medtr3g091400) (see Table S2 and [37]). Values of relative transcript levels were the mean of three biological replicates. Fold induction was calculated by normalizing the data for each time series to the samples of wild-type $0 \mathrm{dpi}$ (time course experiment), to mock inoculated wild-type $14 \mathrm{dpi}$ (experiments with S. meliloti 1021 mutants) and to the M. truncatula wild-type samples (expression analyses in plant mutants). Primers that were used for qRT-PCR are used in previous $[37,38]$ or this studies and listed in Supplementary Table S2. Unpaired Student's $t$-test was carried out on our RT-qPCR data sets to determine statistical significance.

\subsection{Generating Constructs and Complementation Experiments Accomplished by Agrobacterium rhizogenes Transformation}

Constructs for transformation and subcellular localization experiments were generated with the help of the Gateway Technology (Life Technologies). Fragments were amplified with Phusion DNA Polymerase (Thermo Fisher Scientific, Carlsbad, CA, USA) using mth2-62p5 BAC clone as a template and was cloned into pDONR201 vector by homologue recombination. After verification of the sequences, destination clones were generated by LR clonase II-mediated recombination. The destination vectors used were pKGW-R (complementation experiments), pKGWFS7-RR (promoter- $\beta$-glucuronidase (GUS) assay) pK7WGF2-RR and derivative with -pEF1 $\alpha$, pK7FWG2-RR, and pK7FWG2 $\triangle \mathrm{p} 35 \mathrm{~S}$ (GFP or myc-tag experiments). Destination vectors that were modified and used for cloning were obtained from Plant Systems Biology, VIB-Ghent University, in which the DsRed transformation marker was cloned.

To test the complementation capacity of NAD1 and its deletion or truncated derivatives, constructs with the complete NAD1 gene (exon1, intron and exon2) with or without the presumed 78 base pairs (bp) intron in exon 1 and only exon 1 of NAD1 with or without the presumed $78 \mathrm{bp}$ intron in exon 1 were prepared. The NAD1 and its mutant derivatives were expressed from a $410 \mathrm{bp}$ native promoter and 
terminated by the $400 \mathrm{bp}$ long UTR region of NAD1. Constructs were introduced into ARqua1 strain of $A$. rhizogenes and used for hairy root transformation, as described by [39]. The vectors contained the DsRed reporter gene to identify transgenic hairy roots. Transformed plants were planted into zeolite substrate and inoculated with S. medicae WSM419 (pXLGD4). Following 3-5 weeks post inoculation, nodules were collected, fixed, sectioned, and stained for LacZ activity.

For subcellular localization experiments, DNA fragments were generated by PCR on $M$. truncatula A17 genomic DNA or cDNA templates using Pfu Ultra II Fusion DNA Polymerase (Stratagene, San Diego, USA) and gene-specific primers. To generate entry clones, PCR fragments were introduced into pCR8-GW-TOPO vector (Life Technologies). To resolve the subcellular localization of the NAD1 protein, the NAD1 cDNA was recombined from the pCR8GW-TOPO entry clone into the pK7WGF2-R and pK7FWG2-R vectors carrying the AtUBQ10::DsRED1 fluorescent marker gene [40]. For co-localization experiments, p35S::GFP-NAD1 fusion was created in the pMDC43 vector [41].

\subsection{Transient Gene Expression in Nicotiana benthamiana Epidermal Cells}

Plasmid constructs were electroporated into A. tumefaciens strain, C58C1. Transformant agrobacteria carrying plasmids were selected on Luria-Bertani (LB) [42] medium containing appropriate antibiotics at $28{ }^{\circ} \mathrm{C}$. A single colony was inoculated to $5 \mathrm{~mL}$ of LB medium, and the culture was grown at $28{ }^{\circ} \mathrm{C}$ in a shaker for $48 \mathrm{~h}$. The cells were transferred to fresh LB medium containing $10 \mathrm{mM}$ MES (2-morpholinoethanesulfonic acid; $\mathrm{pH} 5.6$ ) and $40 \mathrm{mM}$ acetosyringone (1:100 ratio, $v / v)$. After $16 \mathrm{~h}$ of growth at $28{ }^{\circ} \mathrm{C}$, or when the culture reached an OD600 of 3.0, the bacterial cells were collected by centrifugation at $3200 \times g$ for $10 \mathrm{~min}$. The pellet was resuspended in $1 \mathrm{mM} \mathrm{MgCl}_{2}$ at a final optical density at $\lambda=600 \mathrm{~nm}$ (OD600) of 1.5. For A. tumefaciens strain p19, a final OD600 of 1.0 was used instead. Acetosyringone at a final concentration of $200 \mathrm{mM}$ was added to the Agrobacterium solution, which was kept at room temperature for at least $3 \mathrm{~h}$ without shaking. For co-infiltration, an equal volume of different Agrobacterium strains carrying plasmids was mixed prior to infiltration. Infiltration of leaves with Agrobacterium cells was conducted by slowly depressing the plunger of a $1 \mathrm{~mL}$ disposable syringe to the surface of fully expanded leaves.

\section{Results and Discussion}

3.1. Mutants Defective in Symbiotic Nitrogen Fixation and Showing Induced Defense Responses Are Deficient in the NAD1 Gene

A collection of $M$. truncatula mutants showing defects in symbiotic nodule development and function was identified and described previously [35]. One of the ineffective mutants in this mutant collection, termed $7 Y$, showed the symptoms of nitrogen starvation and developed slightly cylindrical yellowish or brownish nodules following inoculation with compatible rhizobia ([35] and Supplemenatary Figure S1). The brown pigmentation associated with strong autofluorescence that appeared after inoculation suggested the induction of defense responses in $7 \mathrm{Y}$ mutant nodules ([35] and Figure 1B,G). Based on genetic and sequence analyses described below, another allele of $7 \mathrm{Y}$, the N5896A mutant showing similar nodulation phenotype (Figure 1C,H), was identified in a separate symbiotic screen of a M. truncatula Tnt1/MERE1 insertion mutant collection established in the Jemalong 2HA background [43,44]. 


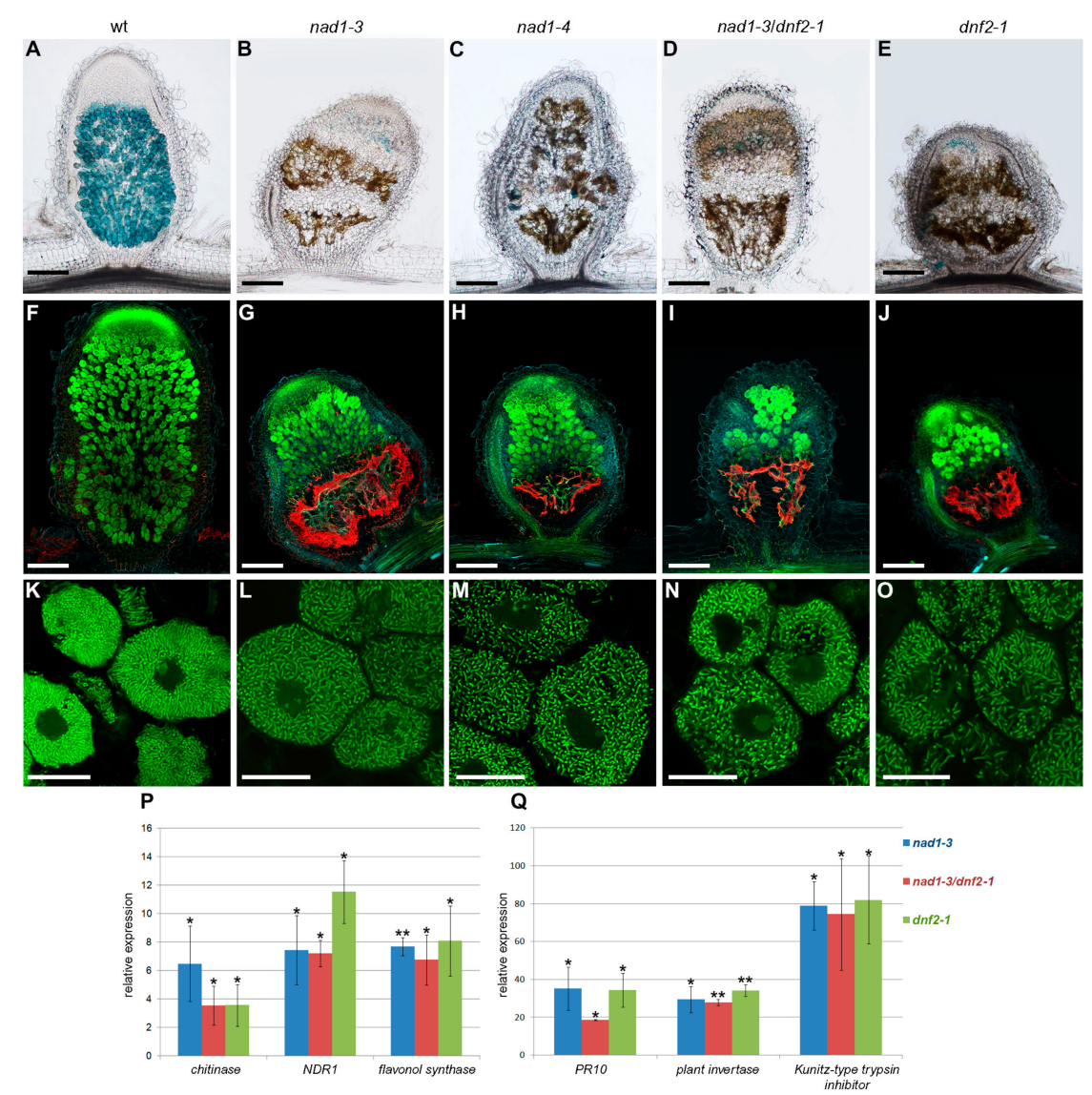

Figure 1. Induction of defense responses in nodules with activated defense 1 (nad1), defective in nitrogen fixation $2(d n f 2)$ and nad1/dnf2 mutant nodules. The degree of rhizobial infection, bacteroid differentiation and the presence of brown pigmentation showing autofluoescence in symbiotically ineffective Medicago truncatula mutants supposed to be deficient in suppression of plant defense responses during the symbiotic interaction. Nodules were harvested 14 days post-inoculation (dpi) with Sinorhizobium medicae WSM419 expressing the lacZ marker gene. Nodule sections were stained for $\beta$-galactosidase activity (A-E) or stained with SYTO13 (F-O) and analyzed by light or confocal microscopy, respectively. Wild-type nodules showed the characteristic zonation of indeterminate nodules (A,F). Nodules of nad1-3 (B,G), nad1-4 (C,H), nad1-3/dnf2 (D,I), and dnf2 (E,J) displayed extensive brown pigmentation that corresponded to the area showing autofluorescence which is pseudocolored in red. Higher magnification revealed elongated bacteroids in the infected cells of the interzone of wild-type nodules (K). Elongated bacteroids were detected in the last layers of infected cells in mutant nodules $(\mathbf{L}, \mathbf{M}, \mathbf{N}, \mathbf{O})$, which indicates the initiation of bacteroid development in these nodules. Scale bars: (A-J) $200 \mu \mathrm{m},(\mathbf{K}-\mathbf{O}) 20 \mu \mathrm{m}$. (P,Q) Transcriptional activation of defense-related genes in the nodules of nad1-3, nad1-3/dnf2 and $d n f 2$ mutants. The expression level of a chitinase, the NDR1, flavonol synthase, the PR10, a plant invertase and a Kunitz-type trypsin inhibitor gene was identified by quantitative reverse transcription PCR 14 dpi with S. medicae WSM419. The transcript levels were identified using three biological replicates and calculated relative to the expression detected in wild-type nodule. Error bars indicate \pm standard error (SE). ${ }^{* *}$ and ${ }^{*}, p \leq 0.01$ and 0.05 , respectively.

Our previous study [35] revealed that 7Y is not an allele of the previously described $d n f$ symbiotic mutants [45], and identified the map position of the 7Y mutant locus on the upper arm of chromosome 7 of M. truncatula between the genetic markers MtB243 and MtB183 ([33] and Figure S2A). A map-based cloning approach was applied to identify the gene affected in the nad1-3 mutant. An extended segregating population of 727 F2 individuals was used to map the mutant locus between genetic markers EF4142291 and h2_96b16t19 (Figure S2A). The analysis of the sequence of this genomic region 
of $153 \mathrm{~kb}$ revealed 24 predicted gene models (Mt4.0 JBrowse) [46] including the nodule specific NAD1 gene (Medtr7g022640) [21], providing a good candidate for the mutated gene in 7Y.

Oligonucleotide primers were synthesized for the NAD1 gene and PCR reactions were carried out to amplify genomic fragments of NAD1 from the $7 Y$ mutant. The sequence analysis revealed a 50-bp deletion starting at 26 bp downstream of the predicted AUG start codon in $7 \mathrm{Y}$; therefore, $7 \mathrm{Y}$ is hereafter termed nad1-3 (Figure 2A). The gene structure of NAD1 available at the Medicago genome database (Mt4.0 JBrowse) is based on an expressed sequence tag (EST) sequence (EST483823; GenBank BG582085.1), predicting that the NAD1 gene consists of four exons encoding a 70 amino acid long putative protein (Mt4.0 JBrowse and Figure 2A). Because the 50-bp deletion is located in the first predicted intron of this NAD1 gene model, cDNA of NAD1 was generated and sequenced to search for other transcript versions. The sequence analysis revealed that the gene is actually composed of two exons and one intron (Supplemenatary Figure S2A). A protein of 96 amino acid residues with two transmembrane domains is encoded in the first exon, as described by [21]. Based on this gene structure, the 50-bp deletion in nad1-3 mutant is located in the first exon of NAD1 (Figure 2A). This deletion generates a frameshift and a premature translation termination in the position $202 \mathrm{bp}$ of the coding sequence, and, thus, a truncated and inaccurate protein with non-NAD1-specific amino acids from the position of the ninth residues.

To identify which Tnt1/MERE1 insertion caused the deficiency in the ineffective symbiotic mutant N5896A, the co-segregation of flanking sequence tags (FSTs) and the mutant phenotype-nitrogen deficiency and accumulation of brownish pigmentation in the nodules-was analyzed in an F2 population generated by self-pollinating an F1 plant originating from a back-cross. The genetic analysis of $40 \mathrm{~F} 2$ plants, including seven homozygote mutants, revealed co-segregation of the mutant phenotype and the presence of a Tnt1 retroelement inserted into the $5^{\prime}$-untranslated region (UTR) of the NAD1 gene (Figure 2A), indicating that this ineffective mutant carries an additional allele of nad1; therefore, N5896A ineffective mutant hereafter termed nad1-4. To analyze the effect of the Tnt1 insertion in the $5^{\prime}$-UTR on the expression of NAD1, the cDNA samples that were prepared from nad1-4 nodules were used in RT-PCR which showed the absence of NAD1 transcript indicating that the Tnt1 insertion in nad1-4 abolished the expression and activity of NAD1 (Supplementary Figure S2B).

A

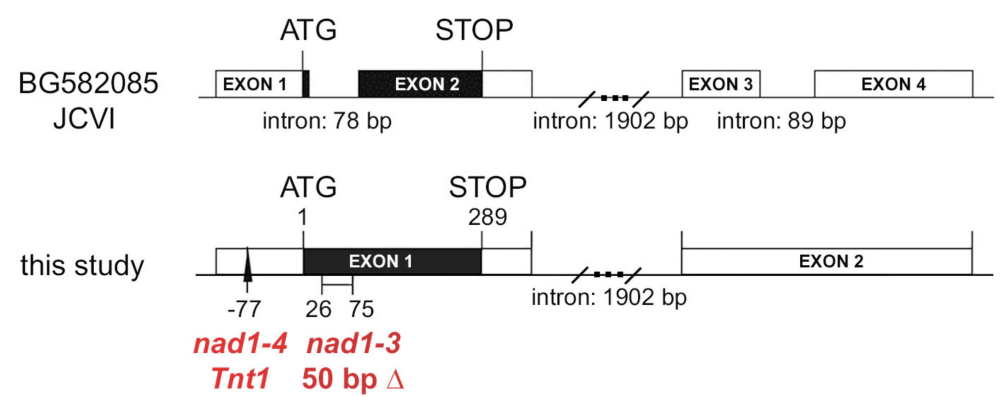

B

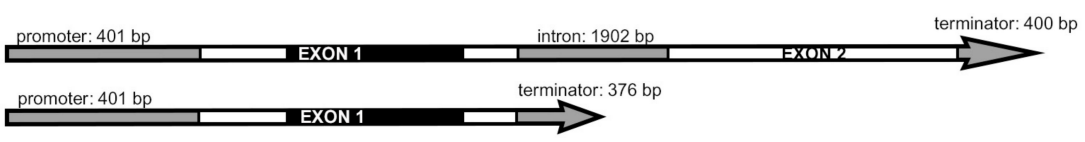

Figure 2. Gene structure of NAD1 supported by experimental data and position of the mutations in nad1-3 and nad1-4 mutants. (A) The gene structure of NAD1 proposed based on expressed sequence tag BG582085 at JCVI (upper image) and the cDNA sequence identified in this study. Black boxes represent the coding sequences while blank boxes show non-coding exons. The 50-bp deletion in nad1-3 and the Tnt1 insertion in nad1-4 are shown on the cDNA-based gene structure. (B) The schematic presentation of the two constructs used in complementation experiments. The longer construct could completely, while the shorter one could only partially restore the symbiotic phenotype of nad1-3 and nad1-4 mutants (Supplementary Figure S3). Grey bars represent promoter and intron sequences, grey arrows show the terminator regions. Blank bars present exons, while black regions show the coding sequence of NAD1. 


\subsection{Both Exons of NAD1 Are Required for Complete Rescue of the Symbiotic Phenotype of nad1-3 and nad1-4 Mutants}

In order to test whether the entire transcript of $N A D 1$ harboring two exons or other alternative transcripts are able to restore the symbiotic phenotype of nad1-3 and nad1-4, we carried out genetic complementation experiments using the following constructs: the genomic copy of NAD1, the first exon (containing the entire coding sequence for the protein), the first exon with a 78-bp deletion mimicking the first intron predicted at the Medicago genome database based on the BG582085 EST and the whole gene with the same 78-bp deletion fused to the native NAD1 promoter (Figure S3). These constructs were introduced into nad1-3 and nad1-4 roots using Agrobacterium rhizogenes mediated hairy root transformation. The roots were inoculated with S. medicae strain WSM419 (pXLGD4), and the symbiotic phenotype was assessed for the presence of infected cells in the nodules with the help of X-gal staining, as well as for the vanishing of the brown pigmentation, the hallmark of the nad1 mutation. Brownish empty nodules were only formed on the nad1-3 roots transformed either with the empty vector (Supplementary Figure S3D-F) or the constructs harboring the 78-bp deletion that mimics the first intron prediction at the Medicago genome database, based on the BG582085 EST sequence (Supplementary Figure S3L,N). This result proved that the lack of this sequence presumed to be the "first intron" abolishes the function of NAD1, so it is an integral part of the first exon. The mixture of wild-type nodules with proper zonation (Supplementary Figure S3J) and nodules showing brown pigmentation (Supplementary Figure S3K) developed on nad1-3 roots transformed with the first exon harboring the coding sequence for the NAD1 protein, suggesting the loss of proper regulation of NAD1 in the absence of the rest of the transcript and/or the intron and/or the $3^{\prime}$-UTR to restore the symbiotic phenotype. The nodules on nad1 mutants transformed with the complete NAD1 gene were pink, indicating that they were functional nodules (Supplementary Figure S3G). The X-gal stained nodules showed the typical zonation of the indeterminate nodules with invaded cells by rhizobia (Supplementary Figure S3I,M), demonstrating that the complete gene is essential for the full rescue of the symbiotic phenotype of nad1-3.

The results of the complementation experiments confirmed the proper structure of the NAD1 gene, and, in addition, the requirement of the non-coding second exon for the complete capacity of NAD1 to restore the symbiotic phenotype was demonstrated. These results point out the potential regulatory function of exon2 and/or 3'UTR of NAD1, which, in turn, suggests that the BG582085 sequence correspond to either an aberrant transcript or an alternative spliced product of the NAD1 gene.

\subsection{NAD1 Is Expressed in Infected Cells and the Gene Product Localizes to the Endoplasmic Reticulum}

The expression of $N A D 1$ is nodule specific and its activation requires the formation of symbiotic nodules [21]. The expression of NAD1 was monitored during the nodule development using quantitative RT-PCR. The NAD1 is expressed at a low level at 4 dpi with rhizobia and a strong increase in expression was detected at $6 \mathrm{dpi}$, and subsequent time points in wild type nodules (Figure 3A). In nad1-3 nodules, the NAD1 was activated similarly, but it was expressed at a lower level when compared to wild type samples between 8 and $21 \mathrm{dpi}$ (Figure 3A). We detected a great decline in the NAD1 expression $21 \mathrm{dpi}$, which is probably associated with the advanced stage of the necrotic phenotype of nad1-3 nodules.

To further analyze the expression pattern of $N A D 1$, its promoter fused to the $\beta$-glucuronidase reporter gene was introduced into wild-type $M$. truncatula roots using A. rhizogenes-mediated hairy root transformation. The roots were inoculated with $S$. medicae strain WSM419 (pXLGD4) and nodules on transformed roots were monitored for GUS activity using 5-bromo-6-chloro-3-indolyl $\beta$-D-glucopyranosiduronic acid cyclohexylammonium salt (Magenta-Gluc) substrate and then stained for $\beta$-galactosidase activity to visualize the presence of rhizobia at 14 dpi. GUS activity was found in the cells of the invasion zone, the intermediate zone, and the nitrogen fixation zone, as well (Figure 3B). All of these cells were occupied by rhizobia (Figure 3C), indicating that NAD1 is expressed in the infected cells of the symbiotic nodule. 
The observed expression pattern of NAD1 was in agreement with RNA-sequencing (RNA-seq) data of different nodule zones obtained by laser-capture microdissection [47]. The NAD1 gene is induced in the infection zone and reached its maximum activity in the transition between the infection and nitrogen fixation zones, and maintained in the nitrogen fixation zone (Figure 3D). Based on the RNA-seq data, the DNF2 gene also required for the suppression of plant immunity during nitrogen fixing symbiotic interaction [19], shows co-expression with NAD1 in the zones of $M$. truncatula nodules (Figure 3D). The expression pattern of NAD1 in the nodule zones indicates the continuous requirement of NAD1 in infected nodule cells during the symbiotically active lifetime of the nodule.
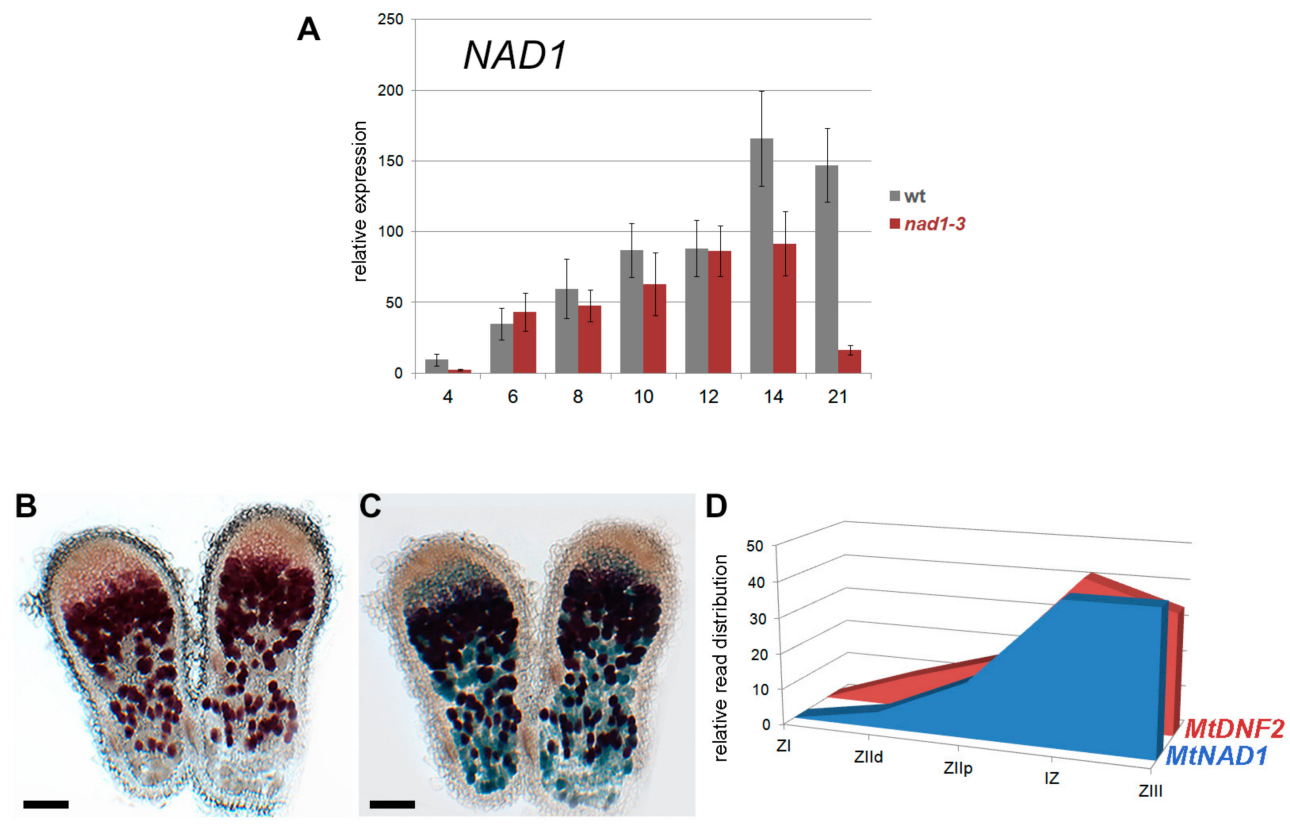

Figure 3. NAD1 is induced following rhizobial inoculation and predominantly expressed in the intermediate and nitrogen fixation zones of Medicago truncatula nodules. (A) The expression level of NAD1 during nodule development in wild-type Jemalong and nad1-3 M. truncatula plants inoculated with S. medicae WSM419 (pXLGD4). The transcript levels were identified by reverse transcription quantitative polymerase chain reaction (RT-qPCR) using three biological replicates and calculated relative to the expression detected in wild-type at $0 \mathrm{dpi} ; x$-axis shows dpi. The results were normalized using an $U B Q$-like gene and PTB. Error bars indicate \pm SE. (B-D) NAD1 is expressed in the infected cells of the infection zone, the intermediate zone and the nitrogen-fixation zone of $M$. truncatula nodules. The NAD1 promoter- $\beta$-glucuronidase (GUS) fusion reporter construct ( $p N A D 1:: G U S$ ) was introduced into the roots of wild-type plants with Agrobacterium rhizogenes mediated hairy root transformation. Roots were inoculated with S. medicae WSM419 expressing the lacZ reporter gene. Nodules on transformed roots at $14 \mathrm{dpi}$ were stained first for GUS activity using the (B) Magenta-Gluc substrate followed by staining for (C) $\beta$-galactosidase activity to display the presence of rhizobia. Scale bars: $200 \mu \mathrm{m}$. (D) Relative spatial expression of NAD1 and DNF2 generated with RNA sequencing of different nodule zones obtained with laser-capture microdissection described in the study by [47]. Both NAD1 and DNF2 are expressed in the zones of the indeterminate nodule of M. truncatula containing colonized cells. ZI: zone I (meristem); ZIId: invasion zone distal; ZIIp: invasion zone proximal; IZ: intermediate zone; ZIII nitrogen-fixation zone.

The sub-cellular localization of the proteins might help to elucidate their functional properties. The NAD1 is predicted to have two transmembrane domains [21], suggesting to be localized to the plasma membrane and/or subcellular membrane compartment. In order to study the localization of NAD1, constructs coding for NAD1 proteins tagged either C- or N-terminally with GFP or c-myc epitopes were created and introduced into nad1-3 roots using hairy root transformation. Unfortunately, 
none of the constructs restored the symbiotic phenotype, indicating that these tags were probably interfered with the function of NAD1 (data not shown). To further investigate the subcellular localization of NAD1, the constructs of N- and C-terminal GFP fusions of the full-length NAD1 cDNA were expressed transiently under the control of the CaMV p35S promoter in Nicotiana benthamiana leaves. According to the detected GFP fluorescence in the leaf epidermal cells, NAD1 was found to be associated exclusively with the endoplasmic reticulum (ER) membrane network (Figure 4). In order to confirm the localization pattern of the NAD1 protein, the p35S::GFP-NAD1 fusion was co-transformed with organelle marker constructs [48] harboring well-established targeting sequences fused to mCherry. We could not detect any significant overlap with the Golgi, tonoplast and peroxisome-specific markers (data not shown), however NAD1 co-localized with the ER-specific marker (Figure 4C). NAD1 codes for a small protein with a $10.7 \mathrm{kDa}$ molecular weight. It has been generally admitted that the diffusion limit set by the nuclear pore for protein is $60 \mathrm{kDa}$. Moreover, the nuclear localization of a GFP3 oligomer protein, whose size is around $90 \mathrm{kDa}$, was observed recently [49]. Thus, GFP fusions below this size without any localization signal, theoretically, can enter into the nucleus by passive diffusion. When considering the fact that GFP-NAD1 chimeric protein is still under this size limit ( $38 \mathrm{kDa})$, there was a theoretical chance that GFP carries the small NAD1 into the nucleus. To exclude this possibility, we co-expressed the p35S::GFP-NAD1 constructs with the pUbq10::RFP-NSP1 [40], showing strong nuclear localization. According to this experiments, the GFP-NAD1 fusion protein was clearly excluded from the nucleus (Figure 4F).

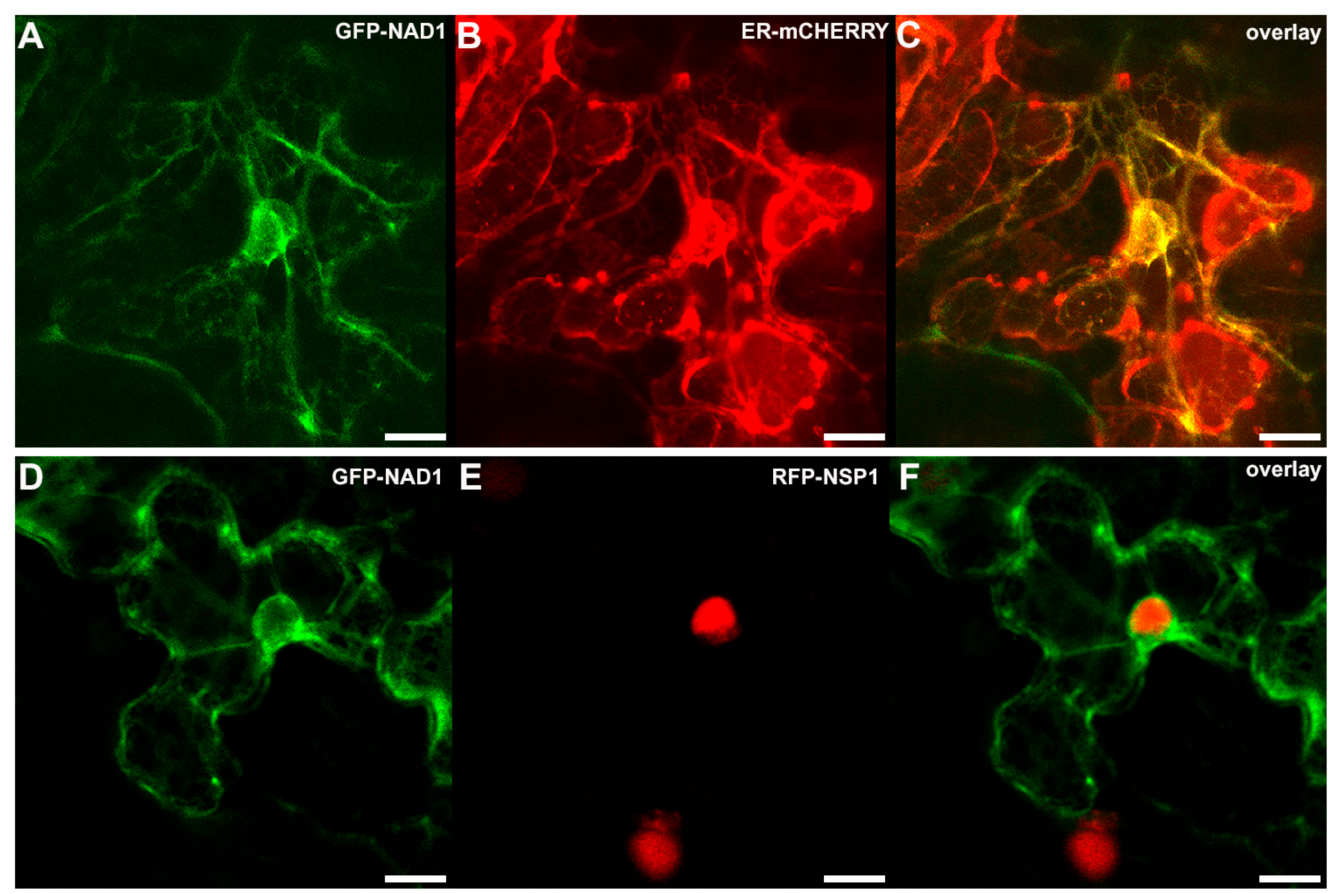

Figure 4. Co-localization of NAD1 with localization control constructs in Nicotiana benthamiana leaf epidermal cells. The $p 35 S:: G F P-N A D 1$ and the ER marker $p 35 S:: E R$-mCherry or the nucleus marker $p U b q 10:: R F P-N S P 1$ constructs were co-transformed transiently into Nicotiana benthamiana leaves. The localization of the tagged proteins was imaged by confocal microscopy. The signal of GFP-NAD1 was detected in the endoplasmic reticulum (ER) network (A,D), which was confirmed by the co-localization with the mCherry signal targeted to the ER (B). The GFP-NAD1 is excluded from the nucleus but NSP1 shows nucleus localization (E). Panels C and F show overlay images of A and B, D and E, respectively. Scale bars: (A-I) $10 \mu \mathrm{m}$.

Our transient co-localization studies in N. benthamiana leaves suggesting the association of the NAD1 signal to the endoplasmic reticulum (ER) is in agreement with the previous results that were 
obtained from localization studies in restored functional nodules and in Arabidopsis protoplasts [21]. In this previous study, the flag-tagged NAD1 restored the symbiotic phenotype of nad1 nodules, indicating that the flag-tag did not interfere with the activity of NAD1 and the more sensitive immunofluorescence assay detected the signal of NAD1 on ER. The ER localization of NAD1 proved by three independent methods supports plausibility of the association of NAD1 to the ER. The ER serves many general functions in the cell, and have a role in protein and lipid biosynthesis and transport, protein folding, signaling (calcium storage) [50], and even in immunity [51], which can inspire several theories about the actual function of NAD1 in the root nodule symbiotic interaction.

\subsection{The Defense Responses Are Induced Simultaneously in nad1 and dnf2 Mutants}

The accumulation of brown pigmentation that was reported in the nodules of the M. truncatula dnf2 mutant [19] was similar to those detected in nad1-3 and nad1-4 nodules (Figure 1). To characterize in more details and discriminate them if possible, the progression of the rhizobial infection in the nodules was analyzed and defense responses were compared in these and in generated double mutants. For this, longitudinal sections of wild-type, nad1-3, nad1-4, dnf2-1, and nad1-3/dnf2-1 double mutant nodules at 14 dpi with Sinorhizobium medicae WSM419 (pXLGD4) constitutively expressing the lac $Z$ gene were stained for $\beta$-galactosidase activity and were investigated by light and fluorescence microscopy. Wild-type nodules showed the typical zonation of indeterminate nodules with fully infected cells in the nitrogen fixation zone (Figure 1A), but nad1, dnf2, and nad1/dnf2 mutant nodules did not show strong $\beta$-galactosidase activity, indicating the low occupancy of rhizobia in nodule cells (Figure 1B-E). The nodulation phenotype of the single nad1, dnf2, and the nad1/dnf2 double mutants were indistinguishable, indicating that the two mutations affect the same or very similar pathways. Staining with X-gal did not clearly reveal the zonation of the mutant nodules, therefore, they were further analyzed by confocal laser scanning microscopy using the nucleic acid-binding dye SYTO13 [52]. Wild-type and mutant nodules did not show differences in the infection zone and the transition between the infection and nitrogen fixation zones (Figure 1F-J). In wild-type nodules, differentiated bacteria in the interzone were oriented toward the vacuoles (Figure $1 \mathrm{~K}$ ). In contrast, in the last layers of infected cell in the interzone of mutant nodules, rhizobia were disordered and slightly elongated (Figure 1L-O). The mutant nodules in the fixation zone were devoid of bacteria (Figure 1G-J). Moreover this region displayed strong autofluorescence in all of the mutant nodules (Figure 1G-J), as described previously for nad1 nodules [21,35], suggesting the accumulation of phenolic compounds. The presence of phenylpropanoids was confirmed with the potassium permanganate/methylene blue staining procedure that reveals polyphenolics with blue coloration and with the toluidine blue dye which stained phenolic compounds dark greenish (Figure 5J-L,P-R and Figure 6A-E). The deposition of polymeric phenols is considered as a defense response [53], and, therefore, the induction (or lack of suppression) of defense responses can be anticipated in nad1, dnf2, and nad1/dnf2 mutant nodules. To assess the activation of plant defense responses in nad1-3, dnf2, and nad1-3/dnf2 nodules, we monitored the transcriptional activation of defense-related marker genes at $14 \mathrm{dpi}$ with $\mathrm{S}$. medicae strain WSM419 using quantitative RT-PCR. A chitinase (Medtr3g118390), the NDR1 (a Non-race-specific Disease Resistance, Medtr5g076170), a flavonol synthase (Medtr5g055680), a PR10 (Medtr2g035150), a plant invertase (Medtr4g101760), and a Kunitz-type trypsin inhibitor (Medtr6g078250) defense-related genes were up-regulated in the nad1-3, dnf2-1, and nad1-3/dnf2-1 double mutant nodules (Figure 1P,Q), confirming induced defense responses, similarly, as it was found previously in the M. truncatula dnf2 [19] and symcrk [20] mutants.

As commented before, microscopy studies revealed that nodules of nad1-3 and nad1-4 mutants showed brown pigmentation that fluoresced, indicating the accumulation of phenolic compounds at $14 \mathrm{dpi}$ (Figure 1). To define at what stages of the symbiotic nodule development the defense responses are activated, the time course of phenolic compound accumulations in nodules was analyzed using potassium permanganate/methylene blue staining. In wild-type Jemalong nodules, cells were colonized by bacteria in the infection, inter and nitrogen fixation zones and no polyphenol 
accumulation could be detected at any time point of the analysis (Figure $5 \mathrm{~A}, \mathrm{D}, \mathrm{G}, \mathrm{J}, \mathrm{M}, \mathrm{P}$ ). In the mutant nodules, no polyphenolic staining was observed at 6 dpi (Figure 5E,F). Blue precipitates, indicating that the presence of polyphenolics could be detected at 8 and $14 \mathrm{dpi}$ that correspond to the sites of brown pigmentation (Figure 5K,L,Q,R). Consistent with the accumulation of phenolic compounds, the expression of defense-related genes were strongly activated at 8 (the chitinase and PR10) and 10 dpi (NDR1 and the Kunitz-type trypsin inhibitor) in nad1-3 mutant nodules, relative to wild-type (Figure 5S,T).

To reveal any differences in the induction of plant defense responses, the kinetics of the appearance of brown pigmentation was analyzed in nad1-3, dnf2-1 and nad1-3/dnf2-1 double mutants inoculated with $S$. meliloti strain WSM419 (pXLGD4). Nodules were stained for $\beta$-galactosidase activity and the microscopy analysis revealed invaded nodule cells in the mutants at $6 \mathrm{dpi}$ and the brown pigmentation appeared at 8dpi in $d n f 2-1$ and nad1-3/dnf2-1 nodules, similar to nad1-3 (Supplementary Figure $S 4 H, M, R$ ). These results indicate that nad1 and $d n f 2$ mutant nodules not only show comparable induction of defense-like responses but these reactions exhibit similar kinetics, as well (Figure 5 and Supplementary Figure S4).

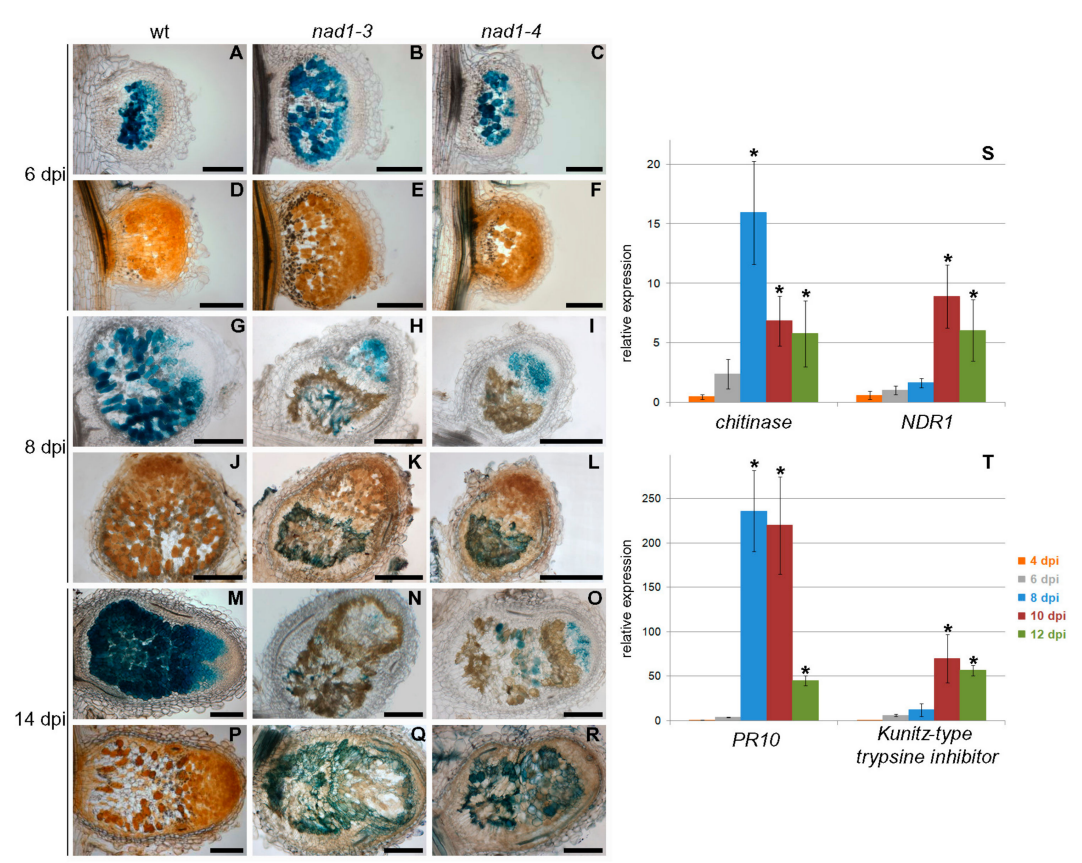

Figure 5. (A-T) Defense responses are activated in nad1-3 and nad1-4 nodules between 6 and 8 dpi with S. medicae WSM419 carrying the GUS reporter gene. (A-R) The brown pigmentation in nad1 nodules corresponds to accumulation of phenolic compounds. Nodule sections of wild-type (first column) and nad1-3 (second column) and nad1-4 (third column) mutants were stained for the activity of $\beta$-glucuronidase (A-C, G-I,M-O) to detect the presence of bacteria and with potassium permanganate and methylene blue dye (D-F,J-L,P-R) to visualize phenolic compounds in blue at 6 (A-F), 8 (G-L) and 14 dpi (M-R). Wild-type and mutant nodules are colonized equally and no accumulation of polyphenolics was detected $6 \mathrm{dpi}$ (A-F). The brown pigmentation appeared in nad1 nodules at $8 \mathrm{dpi}$ $(\mathbf{H}, \mathbf{I})$ overlaps with the region containing polyphenols $(\mathbf{K}, \mathbf{L})$, indicating the activation of defense responses in mutant nodules. The accumulation of polyphenolic compounds expanded in increased area of the mutant nodules at $14 \mathrm{dpi}(\mathbf{N}, \mathbf{O}, \mathbf{Q}, \mathbf{R})$ but brown pigmentation was not detected in wild-type nodules at any time points. Scale bars: (A-R) $200 \mu \mathrm{m}$. Temporal induction of defense-related genes (a chitinase, NDR1, PR10, and a Kunitz-type trypsin inhibitor) in nad1 nodules analyzed with quantitative RT-PCR following S. medicae WSM419 inoculation. Relative transcript levels at different time points were calculated in relation to wild-type plants $(\mathbf{S}, \mathbf{T})$. Error bars indicate $\pm \mathrm{SE}$. ${ }^{*} p \leq 0.05$. 
3.5. Defense-Like Responses Are Induced upon the Internalization of the Symbiotic Nodule Cells by Rhizobia and Rapidly Induce the Degradation of Host and Bacterial Cells

Because the defense responses were induced between 6 and $8 \mathrm{dpi}$ in nad 1 and $d n f 2$ nodules, we analyzed the viability of rhizobia using live and dead staining with the fluorescent nucleic acid-binding dye, SYTO9 and PI using confocal microscopy. SYTO9 detects living bacteria showing green fluorescence while plant nuclei and membrane compromised bacterial cells take up PI and show red fluorescence. At $6 \mathrm{dpi}$, viable green fluorescent bacteria were detected in wild-type and nad1-3, dnf2-1 and nad1-3/dnf2-1 double mutant nodules and only the meristematic region composed of non-infected small cells rich in cytoplasm as well as plant nuclei displayed red fluorescence (Supplementary Figure S5B,C,H,I,N,O,T,U). In the sections of 8 dpi wild-type nodules, bacteria fluoresced green (Supplementary Figure S5E,F). In mutant nodules, a large area with autofluorescence appeared few layers below the invaded cells and only few cells containing dead red fluorescent bacteria could be observed in the transition zone between the invaded cells and the area accumulating phenolic compounds, suggesting the rapid disintegration of dead bacteria in nodule cells (Supplementary Figure S5K,L,Q,R,W,X).

To further analyze the induced defense responses in nad1-3 nodules at ultrastructural level, electron microscopy studies on 8 and 18 dpi nodules were carried out. The SEM analysis of developing 8 dpi wild-type nodules detected elongated bacteroids that were orientated towards the central vacuoles and were encompassed by cytoplasmic matrix in the cells of the first layers of the nitrogen fixation zone (Supplementary Figure S6B,C). The nodule cells in the corresponding region in nad1-3 nodules have thickened cell walls and they were either devoid of rhizobia or contained slightly elongated, disordered, and aggregated bacteria without surrounding cytoplasmic matrix, indicating the degradation of bacterial and plant cells (Supplementary Figure S6E,F). Transmission electron microscopy images showed differentiated bacteroids, reaching 6-8 $\mu \mathrm{m}$ in length, in the nitrogen fixation zone of 18 dpi wild-type nodules (Supplementary Figure S6G,J). In nad1-3 nodules, cells in the last layers of infected cells had thickened cell walls and often cell wall-like deposits surrounding electron dense necrotic bacteria were detected (Supplementary Figure S6H,I). In root distal part of the nad1-3 nodules corresponding to zone III, disorganized cellular structure and hydrolyzed cell wall remnants were identified, indicating the necrosis of both the host cells and bacteroids (Supplementary Figure S6K). Older cells in the proximal part of the nodules were almost empty, showing the advanced degradation of symbiotic cells in nad1-3 nodules (Supplementary Figure S6L).

In our experimental conditions, the cells in the invasion and the first layer of the intermediate zone of the indeterminate $M$. truncatula nodules were invaded by rhizobia at 6 dpi, but no visible signs of induced defense response or induction of defense-related genes was observed in nad1 nodules (Figure 5, Supplementary Figures S4 and S5). In contrast, the viability staining of bacteroids, the appearance of accumulated polyphenolics and the activation of defense-associated genes suggested the loss of the control over the plant immune responses in nad1 nodules at $8 \mathrm{dpi}$. Moreover, electron micrographs of nad1-3 showed the rapid death of rhizobia and the lysis of the host cell resulting in almost empty cells in the proximal part of the nodule, indicating the quick progression of necrosis in 8 dpi nad1 nodules (Supplementary Figure S6). Our microscopy analyses highlighted that bacteria not only filled the host cells in the transition zone between invasion and nitrogen fixation zone, but their differentiation was initiated in nad1 nodules.

\subsection{The Function of NAD1 Precedes DNF1 and NAD1 Acts Independently and Prior to Rhizobial BacA in the Symbiotic Process}

To further explore at what stage the symbiotic interaction is blocked, the nodulation phenotypes of nad1-3, nad1-4, nad1-3/dnf1-1, nad1-3/dnf2-1 and nad1-3/lin-2 mutant plants were analyzed after inoculation with rhizobial strains deficient in the production of the NF $(\operatorname{nod} A)$ or the succinoglycan EPS I (exoY) or defective in bacteroid differentiation (bac $A$ ). To assess the induction of plant defense responses in wild-type and mutant nodules that were arrested at different stages of the symbiotic 
interaction, sections of the nodules were stained with toluidine blue and analyzed for the presence of phenolic compounds at $14 \mathrm{dpi}$. Inoculation of the symbiotically less effective rhizobial strain S. meliloti 1021 [54] caused a similar accumulation of polyphenolics in nad1, dnf2, and nad1/dnf2 nodules (Figure 6A-E) that was found with S. medicae WSM 419, indicating that the nad1 phenotype is not strain dependent. This allowed for us to analyze the symbiotic phenotype of wild-type and nad1-3, nad1-4, dnf2-1, and nad1-3/dnf2-1 mutants that were inoculated with symbiotic bacterial mutants generated in the S. meliloti 1021 strain.

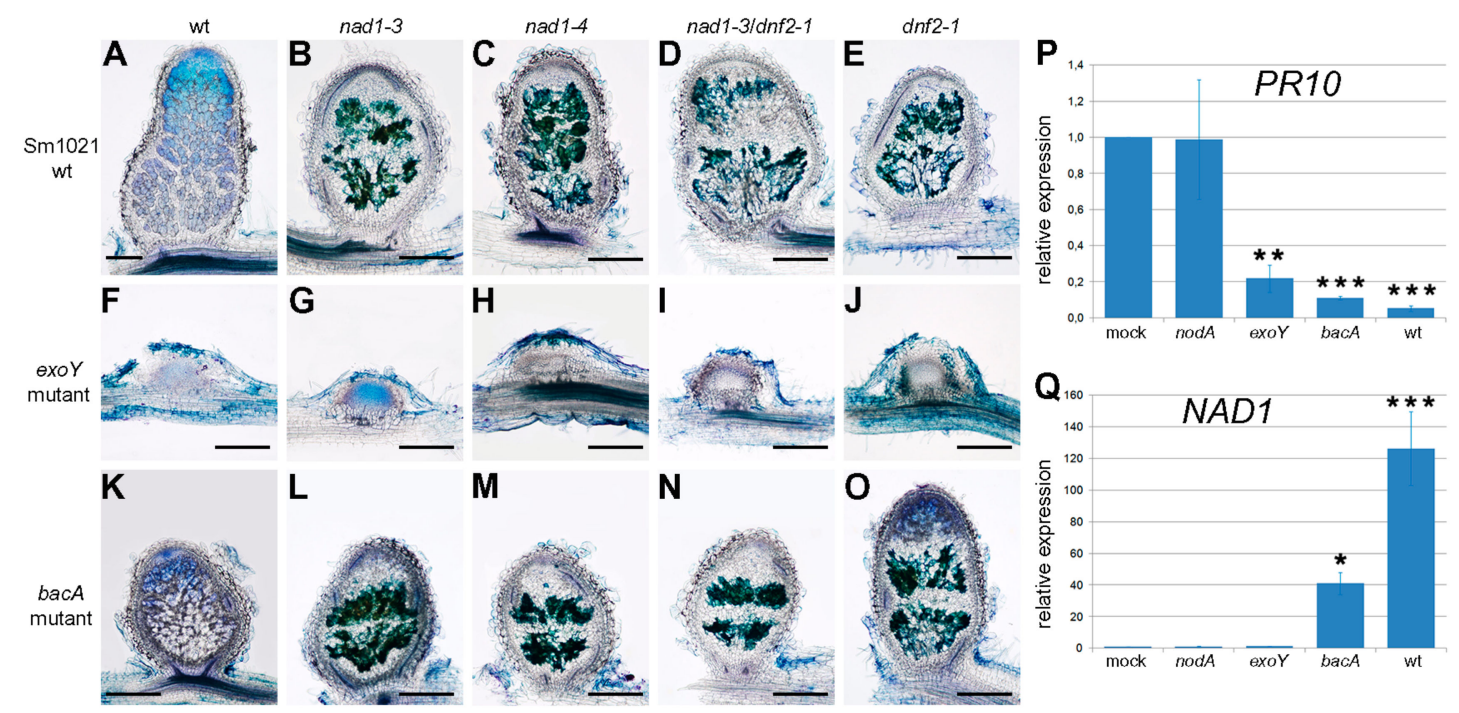

Figure 6. Positioning of the function of NAD1 in the symbiotic process. Sections of wild-type (A,F,K), nad1-3 (B,G,L), nad1-4 (C,H,M), nad1-3/dnf2-1 (D,I,N), and $\operatorname{lnf2-1}(\mathbf{E}, \mathbf{J}, \mathbf{O})$ nodules were stained with toluidine blue to detect accumulation of phenolic compounds $14 \mathrm{dpi}$ with wild-type $S$. meliloti 1021 (A-E) or its exoY (F-J) and bacA (K-O) mutant derivatives. Nodule primordia induced by exoY mutant rhizobia displayed no staining of polyphenols, but mutant nodules elicited by $S$. meliloti wild-type or $b a c A$ mutant stained dark green showing the accumulation of phenolic compounds which indicates that NAD1 acts prior bacterial differentiation. Scale bars: (A-O) $200 \mu \mathrm{m}$. The PR10 and NAD1 genes are expressed inversely in nodules containing released rhizobia in $14 \mathrm{dpi}$ nodules $(\mathbf{P}, \mathbf{Q})$. The relative expression level of PR10 and NAD1 was analyzed in wild-type (Jemalong) nodules with quantitative RT-PCR 14 dpi with wild-type and mutant S. meliloti 1021 derivatives blocked at different stages of the symbiotic process. The transcript levels were calculated relative to the expression detected in non-infected roots (mock). Values of relative transcript levels are the mean of three biological replicates. Error bars indicate \pm SE. ${ }^{* *},{ }^{* *}$ and ${ }^{*}, p \leq 0.001,0.01$ and 0.05 , respectively.

The exoY mutant of S. meliloti strain 1021 defective in the production of succinoglycan fails to initiate infection thread formation, hence ineffective nodules without rhizobial invasion are formed on Medicago roots ([55] and Figure 6F). In mutant nodules, no accumulation of the phenolic compounds could be observed at $14 \mathrm{dpi}$, suggesting the requirement of bacterial colonization for the induction of plant defense in these symbiotic mutants (Figure 6F-J).

The BacA protein protects S. meliloti against the antimicrobial activity of NCR peptides [8], and therefore, BacA is essential for bacteroid development in galegoid legumes [56]. bacA mutants induce indeterminate nodule formation on Medicago roots but rhizobia are killed soon after release from infection threads prior to bacteroid differentiation [57]. Accordingly, bacA mutant rhizobia lysed and non-infected cells were observed in wild-type Jemalong nodules (Figure 6K). This inefficient interaction does not trigger phenolic compounds production [23]. In contrast, the nodules of nad1, dnf2-1, and nad1-3/dnf2-1 mutants that were elicited by bacA show accumulation of phenolic compounds, 
indicating that the defense responses were rapidly activated following the release of mutant rhizobia into the host compartment (Figure 6L-O).

To correlate the induction of NAD1 and plant defense responses in nodules elicited by wild-type and symbiotically deficient rhizobial strains, the transcriptional activation of NAD1 and the defense-related PR10 was monitored in wild-type Jemalong roots or nodulated roots at $14 \mathrm{dpi}$. The basic expression level of the PR10 gene detected in nodules elicited by mock or nodulation factor (NF) deficient $S$. meliloti [58] was suppressed following inoculation with wild-type rhizobia or bacteria defective in later stages of the symbiotic process, suggesting the suppression of PR10 upon the initiation of infection thread development (Figure 6P). The induction of the NAD1 expression following the inoculation with bacA mutant and wild-type S. meliloti but not with S. meliloti nodA and exoY mutants indicated the need of bacterial release for the induction of NAD1. These results showed that NAD1 starts to function after the uptake of rhizobia into the host cells but prior rhizobial differentiation in M. truncatula nodules.

The characterization of the mutant phenotype of nad1 and other ineffective symbiotic nodulation double mutants with nad1 enables the determination of the functional hierarchy of the impaired genes. The symbiotic phenotype of single and double mutants of nad1-3, lin-2, ipd3-1, and dnf1-1 were analyzed at $14 \mathrm{dpi}$ with S. medicae (pXLGD4). The lin-2 mutant is deficient in the early stage of the rhizobial symbiotic process and although nodule primordia are formed, the infection thread development is arrested in the root hairs ([59] and Figure 7B). The nodules on ipd3 mutant roots are more developed when compared to lin nodule primordia, but ipd 3 nodules are impaired in release of rhizobia from infection threads, and, thus, bacteria do not colonize nodule cells ([60] and Figure S7C). The nad1-3/lin-2 and nad1-3/ipd3-1 double mutants showed the same defects of infection and bacterial release as lin-2 and ipd3-1, respectively (Figure 7F,G), without phenolics accumulation, indicating that bacterial release and invasion is required for the function of NAD1.

The DNF1 gene coding for a symbiosis-specific component of the secretory pathway is required for bacterial differentiation and symbiosome development and in $d n f 1$ mutant, released bacteria are blocked in the very early stage of bacteroid development [6,7]. In the undeveloped nodules of $d n f 1$, no distinct developmental zones could be observed, but nodule cells were colonized by rhizobia with no accumulation of phenolic compounds (Figure 7D). The presence of phenolic compounds in the nad1-3/dnf1-1 double mutants suggests the activation of plant defense responses (Figure 7H). This was consistent with our previous findings that the proper acting of NAD1 is required before bacterial differentiation.

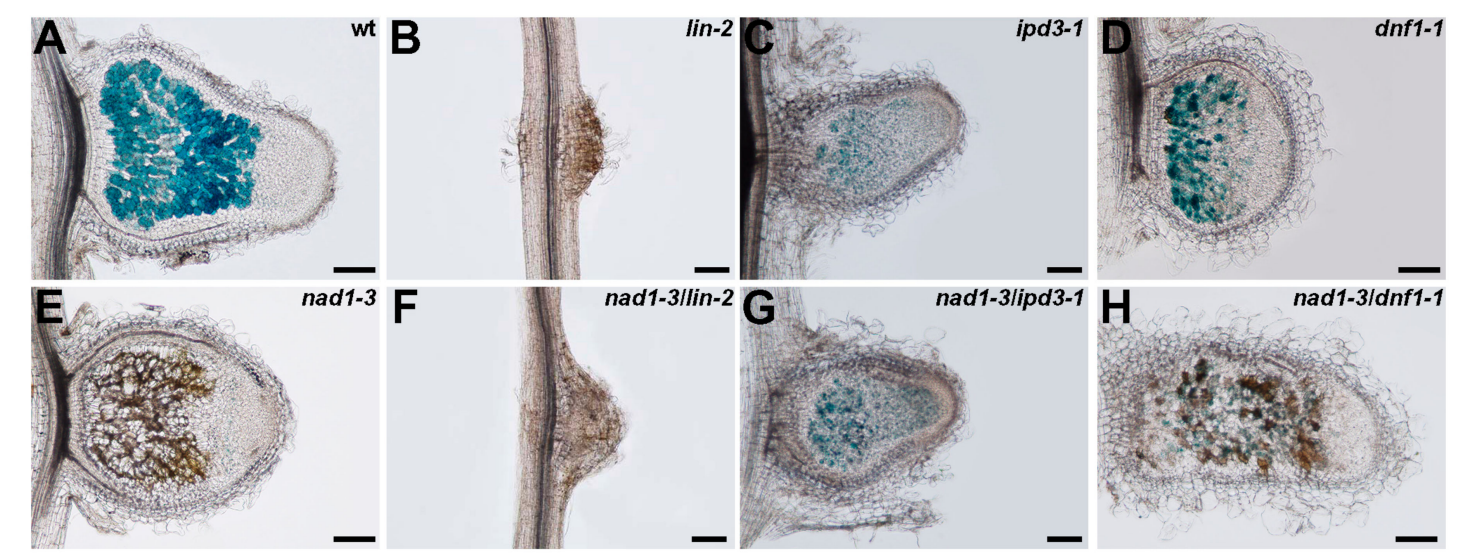

Figure 7. The defense responses are activated in nad1-3 following the internalization of rhizobia but prior to bacteroid differentiation. Nodulation phenotype of wild-type (Jemalong) (A), lin-2 (B), ipd3-1 (C), dnf1-1 (D), nad1-3 (E), nad1-3/lin-2 (F), nad1-3/ipd3-1 (G), and nad1-3/dnf1-1 (H), mutants 14 dpi with S. medicae expressing the lac $Z$ marker gene. The induction of defense response was detected by the presence of natural brown pigmentation (no staining) in mutant nodules. Scale bars: $200 \mu \mathrm{m}$ 
Our microscopy analysis of the nodulation phenotypes of single and double ineffective plant symbiotic mutants that were inoculated with wild-type and symbiotic mutant rhizobia allowed for us to position the NAD1 gene in the symbiotic process. First of all, the nodulation phenotype of nad1 and nad1-3/ipd3-1 double mutants that were inoculated with exoY mutant and wild-type rhizobia, respectively, indicated that bacterial release and colonization of nodule cells are required for the function of NAD1. The observation that $\operatorname{dnf2}$, nad1, and nad1/dnf2 nodules, as elicited by bacA mutant rhizobia, did accumulate phenolic compounds suggested that the repression of plant defense responses is independent of the differentiation of rhizobia at this stage of the interaction. The symbiotic interaction is blocked at the same developmental stage and the expression of the defense-associated genes displayed the similar induction in nad1/dnf2 double mutant as in the single mutant nodules, suggesting that NAD1 and DNF2 operate close together in the same developmental pathway. The observation that the plant defense is suppressed irrespective of the differential status of bacteria was further evidenced by the microscopy analysis of the nad1-3/ dnf1-1 double mutant that was elicited with wild-type bacteria. We detected brown pigmentation in nad1-3/dnf1-1 double mutant nodules, although this defense reaction was not as robust as in nad1-3 nodules, which probably correlates with the lower number of infected cells, and the reduced zonation of $\operatorname{dnf} 1$ mutant nodules possessing mainly an enlarged invasion zone [7]. This result is in agreement with the observation that NAD1 expression was reduced in wild-type plants nodulated with $b a c A$ mutant rhizobia. Taken together, these results indicate that the defense-like responses were induced irrespectively of the differential phase of rhizobia in nad1-3 nodules, similarly to what was found in the $\operatorname{dnf} 2$ mutant [23].

\section{Conclusions}

The establishment of successful root nodule symbiosis requires the suppression of plant immunity in multiple steps during the symbiotic interaction with nitrogen fixing microbes $[18,61,62]$. Once rhizobia are released from infection threads, bacteria colonize nodule cells remaining separated from the plant cytoplasm by the plant-derived symbiosome membrane. Following multiplication and differentiation, infected nodule cells accommodate thousands of bacteria, and, therefore, the regulation of plant defense responses in nodules is critical for the colonization of host cells. Several genes that are involved in the control of defense reactions in symbiotic nodules upon the internalization of rhizobia have been recently identified [19-22]. Nodules of mutant plant defective in NAD1, display uncontrolled plant defense responses, such as accumulation of phenolic compounds, increased level of hydrogen peroxide, and the activation of defense-related genes, which finally resulted in the necrosis of rhizobial and host cells [21].

Here, we described and functionally analyzed two novel mutant alleles of the NAD1 gene. Both the nad1-3 deletion and nad1-4 insertion mutants showed the very similar ineffective symbiotic phenotype and displayed brownish pigmentation in nodules corresponding to the accumulation of phenolic compounds, indicating the induction of defense-associated response, as reported previously in nad1 mutants [21].

The results presented here help us to better understand the functioning of NAD1 in the suppression of plant defense responses during the rhizobial nitrogen-fixing symbiotic interaction. The epistasis analysis using ineffective symbiotic mutants of $M$. truncatula, nodulated with rhizobia defective to form functional nitrogen fixation, suggests the hierarchy of plant mutants in the symbiotic process. Based on these results, the suppression of plant defense responses that are controlled by NAD1 occurs irrespectively of the differentiation status of bacteroids at the early stage of intracellular colonisation of rhizobia. We also presented that NAD1 functions after the release of rhizobia from infection threads, and that activity of NAD1 is required in the infected cells of the functioning nodules.

Supplementary Materials: The following are available online at www.mdpi.com/2073-4425/8/12/387/s1. Figure S1: The symbiotic phenotype of nad1-3 and wild-type (Jemalong) plants, Figure S2: Positional cloning of the nad1-3 locus and confirming the mutations in nad1 alleles, Figure S3: Complementation experiments of nad1-3, Figure S4: Time course analysis of accumulation of phenolic compounds in nad1-3, dnf2-1 and nad1-3/dnf2-1 mutants, 
Figure S5: Viability staining of S. medicae WSM419 rhizobia in nad1-3, dnf2-1 and nad1-3/dnf2-1 mutant nodules, Figure S6: Ultrastructure of the wild-type and nad1-3 nodules, Table S1: $M$. truncatula lines and rhizobial strains used in this study, Table S2: Primers used in this study [37,38].

Acknowledgments: This work was supported by the Hungarian National Research Fund/National Research, Development and Innovation Office grants OTKA- 67576, PD104334/108923, 106068, 119652 and 120122/120300 as well as by the bilateral Hungarian-French collaborative project LEGUMICS (NFÜ grant TÉT_10-1-2011-0397 and ANR grant 2010-INTI3-1602-01). The generation of the Tnt1 insertion lines in M. truncatula Jemalong 2HA genotype was financed in the framework of the European FP6 (FOOD-CT-2004-506223 GRAIN LEGUMES IP, GLIP program). We thank G. Halász, H. Cs. Tolnainé and K. Miró for skillful technical assistance. The authors are especially grateful to the French and Hungarian participant of the LEGUMICS project who contributed to the different communal symbiotic mutant screens.

Author Contributions: Ágota Domonkos, Ernő Kiss, Pascal Ratet, Attila Kereszt, Gabriella Endre and Péter Kaló designed research, Ágota Domonkos, Szilárd Kovács, Anikó Gombár, Ernő Kiss, Beatrix Horváth, Gyöngyi Z. Kováts, Attila Farkas, Mónika T. Tóth, Ferhan Ayaydin, Károly Bóka and Lili Fodor performed the experiments, Ágota Domonkos, Szilárd Kovács, Ernő Kiss, Károly Bóka, Attila Kereszt, Gabriella Endre and Péter Kaló analyzed data, Ágota Domonkos, Attila Kereszt and Gabriella Endre edited the manuscript and Péter Kaló wrote the paper.

Conflicts of Interest: The authors declare no conflict of interest.

\section{References}

1. Oldroyd, G.E.D.; Downie, J.A. Coordinating nodule morphogenesis with rhizobial infection in legumes. Annu. Rev. Plant Biol. 2008, 59, 519-546. [CrossRef] [PubMed]

2. Oldroyd, G.E.D.; Murray, J.D.; Poole, P.S.; Downie, J.A. The rules of engagement in the legume-rhizobial symbiosis. Annu. Rev. Genet. 2011, 45, 119-144. [CrossRef] [PubMed]

3. Jones, K.M.; Kobayashi, H.; Davies, B.W.; Taga, M.E.; Walker, G.C. How rhizobial symbionts invade plants: The Sinorhizobium-Medicago model. Nat. Rev. Microbiol. 2007, 5, 619-633. [CrossRef] [PubMed]

4. Vasse, J.; de Billy, F.; Camut, S.; Truchet, G. Correlation between ultrastructural differentiation of bacteroids and nitrogen fixation in alfalfa nodules. J. Bacteriol. 1990, 172, 4295-4306. [CrossRef] [PubMed]

5. Mergaert, P.; Uchiumi, T.; Alunni, B.; Evanno, G.; Cheron, A.; Catrice, O.; Mausset, A.E.; Barloy-Hubler, F.; Galibert, F.; Kondorosi, A.; et al. Eukaryotic control on bacterial cell cycle and differentiation in the Rhizobium-legume symbiosis. Proc. Natl. Acad. Sci. USA 2006, 103, 5230-5235. [CrossRef] [PubMed]

6. Van de Velde, W.; Zehirov, G.; Szatmari, A.; Debreczeny, M.; Ishihara, H.; Kevei, Z.; Farkas, A.; Mikulass, K.; Nagy, A.; Tiricz, H.; et al. Plant peptides govern terminal differentiation of bacteria in symbiosis. Science 2010, 327, 1122-1126. [CrossRef] [PubMed]

7. Wang, D.; Griffitts, J.; Starker, C.; Fedorova, E.; Limpens, E.; Ivanov, S.; Bisseling, T.; Long, S. A nodule-specific protein secretory pathway required for nitrogen-fixing symbiosis. Science 2010, 327, 1126-1129. [CrossRef] [PubMed]

8. Haag, A.F.; Baloban, M.; Sani, M.; Kerscher, B.; Pierre, O.; Farkas, A.; Longhi, R.; Boncompagni, E.; Herouart, D.; Dall'Angelo, S.; et al. Protection of Sinorhizobium against host cysteine-rich antimicrobial peptides is critical for symbiosis. PLoS Biol. 2011, 9, e1001169. [CrossRef] [PubMed]

9. Libault, M.; Farmer, A.; Brechenmacher, L.; Drnevich, J.; Langley, R.J.; Bilgin, D.D.; Radwan, O.; Neece, D.J.; Clough, S.J.; May, G.D.; et al. Complete transcriptome of the soybean root hair cell, a single-cell model, and its alteration in response to Bradyrhizobium japonicum infection. Plant Physiol. 2010, 152, 541-552. [CrossRef] [PubMed]

10. Lohar, D.P.; Sharopova, N.; Endre, G.; Penuela, S.; Samac, D.; Town, C.; Silverstein, K.A.T.; VandenBosch, K.A. Transcript analysis of early nodulation events in Medicago truncatula. Plant Physiol. 2006, 140, 221-234. [CrossRef] [PubMed]

11. Kouchi, H.; Shimomura, K.; Hata, S.; Hirota, A.; Wu, G.J.; Kumagai, H.; Tajima, S.; Suganuma, N.; Suzuki, A.; Aoki, T.; et al. Large-scale analysis of gene expression profiles during early stages of root nodule formation in a model legume, Lotus japonicus. DNA Res. 2004, 11, 263-274. [CrossRef] [PubMed]

12. Sewelam, N.; Kazan, K.; Schenk, P.M. Global plant stress signaling: Reactive oxygen species at the cross-road. Front. Plant Sci. 2016, 7, 187. [CrossRef] [PubMed]

13. Vasse, J.; Debilly, F.; Truchet, G. Abortion of infection during the Rhizobium meliloti-alfalfa symbiotic interaction is accompanied by a hypersensitive reaction. Plant J. 1993, 4, 555-566. [CrossRef] 
14. Jamet, A.; Mandon, K.; Puppo, A.; Herouart, D. $\mathrm{H}_{2} \mathrm{O}_{2}$ is required for optimal establishment of the Medicago sativa/Sinorhizobium meliloti symbiosis. J. Bacteriol. 2007, 189, 8741-8745. [CrossRef] [PubMed]

15. Montiel, J.; Arthikala, M.K.; Cardenas, L.; Quinto, C. Legume NADPH oxidases have crucial roles at different stages of nodulation. Int. J. Mol. Sci. 2016, 17, 680. [CrossRef] [PubMed]

16. Jones, K.M.; Sharopova, N.; Lohar, D.P.; Zhang, J.Q.; VandenBosch, K.A.; Walker, G.C. Differential response of the plant Medicago truncatula to its symbiont Sinorhizobium meliloti or an exopolysaccharide-deficient mutant. Proc. Natl. Acad. Sci. USA 2008, 105, 704-709. [CrossRef] [PubMed]

17. Niehaus, K.; Kapp, D.; Puhler, A. Plant defense and delayed infection of alfalfa pseudonodules induced by an exopolysaccharide (EPS-I)-deficient Rhizobium meliloti mutant. Planta 1993, 190, 415-425. [CrossRef]

18. Cao, Y.R.; Halane, M.K.; Gassmann, W.; Stacey, G. The role of plant innate immunity in the legume-rhizobium symbiosis. Annu. Rev. Plant Biol. 2017, 68, 535-561. [CrossRef] [PubMed]

19. Bourcy, M.; Brocard, L.; Pislariu, C.I.; Cosson, V.; Mergaert, P.; Tadege, M.; Mysore, K.S.; Udvardi, M.K.; Gourion, B.; Ratet, P. Medicago truncatula DNF2 is a PI-PLC-XD-containing protein required for bacteroid persistence and prevention of nodule early senescence and defense-like reactions. New Phytol. 2013, 197, 1250-1261. [CrossRef] [PubMed]

20. Berrabah, F.; Bourcy, M.; Eschstruth, A.; Cayrel, A.; Guefrachi, I.; Mergaert, P.; Wen, J.Q.; Jean, V.; Mysore, K.S.; Gourion, B.; et al. A nonRD receptor-like kinase prevents nodule early senescence and defense-like reactions during symbiosis. New Phytol. 2014, 203, 1305-1314. [CrossRef] [PubMed]

21. Wang, C.; Yu, H.X.; Luo, L.; Duan, L.J.; Cai, L.Y.; He, X.X.; Wen, J.Q.; Mysore, K.S.; Li, G.L.; Xiao, A.F.; et al. Nodules with Activated Defense 1 is required for maintenance of rhizobial endosymbiosis in Medicago truncatula. New Phytol. 2016, 212, 176-191. [CrossRef] [PubMed]

22. Sinharoy, S.; Torres-Jerez, I.; Bandyopadhyay, K.; Kereszt, A.; Pislariu, C.I.; Nakashima, J.; Benedito, V.A.; Kondorosi, E.; Udvardi, M.K. The $\mathrm{C}_{2} \mathrm{H}_{2}$ transcription factor Regulator of Symbiosome Differentiation represses transcription of the secretory pathway gene VAMP721a and promotes symbiosome development in Medicago truncatula. Plant Cell 2013, 25, 3584-3601. [CrossRef] [PubMed]

23. Berrabah, F.; Ratet, P.; Gourion, B. Multiple steps control immunity during the intracellular accommodation of rhizobia. J. Exp. Bot. 2015, 66, 1977-1985. [CrossRef] [PubMed]

24. Chabaud, M.; Lichtenzveig, J.; Ellwood, S.; Pfaff, T.; Journet, E. Vernalization, crossings and testing for pollen viability. In The Medicago Truncatula Handbook; Mathesius, U., Journet, E.P., Sumner, L.W., Eds.; The Samuel Roberts Noble Foundation: Ardmore, OK, USA, 2007; pp. 1-13.

25. Auriac, M.; Timmers, A. Nodulation studies in the model legume Medicago truncatula: Advantages of using the constitutive EF1a promoter and limitations in detecting fluorescent reporter proteins in nodule tissues. Mol. Plant Microbe Interact. 2007, 20, 1040-1047. [CrossRef] [PubMed]

26. Glazebrook, J.; Walker, G.C. Genetic techniques in Rhizobium meliloti. Methods Enzymol. 1991, $204,398-418$. [PubMed]

27. Debelle, F.; Rosenberg, C.; Vasse, J.; Maillet, F.; Martinez, E.; Denarie, J.; Truchet, G. Assignment of symbiotic developmental phenotypes to common and specific nodulation (nod) genetic loci of Rhizobium meliloti. J. Bacteriol. 1986, 168, 1075-1086. [CrossRef] [PubMed]

28. Martin, M.O.; Long, S.R. Generalized transduction in Rhizobium meliloti. J. Bacteriol. 1984, 159, $125-129$. [PubMed]

29. Ferguson, G.P.; Roop, R.M.; Walker, G.C. Deficiency of a Sinorhizobium meliloti bacA mutant in alfalfa symbiosis correlates with alteration of the cell envelope. J. Bacteriol. 2002, 184, 5625-5632. [CrossRef] [PubMed]

30. Journet, E.; de Carvalho-Niebel, F.; Andriankaja, A.; Huguet, T.; Barker, D. Rhizobial inoculation and nodulation of Medicago truncatula. In The Medicago Truncatula Handbook; Mathesius, U., Journet, E.P., Sumner, L.W., Eds.; The Samuel Roberts Noble Foundation: Ardmore, OK, USA, 2007; pp. 1-6.

31. Chabaud, M.; Boisson-Dernier, A.; Zhang, J.; Taylor, C.; Yu, O.; Barker, D. Agrobacterium rhizogenes-mediated root transformation. In The Medicago Truncatula Handbook; Mathesius, U., Journet, E.P., Sumner, L.W., Eds.; The Samuel Roberts Noble Foundation: Ardmore, OK, USA, 2007; pp. 1-8.

32. Choi, H.K.; Kim, D.; Uhm, T.; Limpens, E.; Lim, H.; Mun, J.H.; Kalo, P.; Penmetsa, R.V.; Seres, A.; Kulikova, O.; et al. A sequence-based genetic map of Medicago truncatula and comparison of marker colinearity with M. sativa. Genetics 2004, 166, 1463-1502. [CrossRef] [PubMed] 
33. Mun, J.H.; Kim, D.J.; Choi, H.K.; Gish, J.; Debelle, F.; Mudge, J.; Denny, R.; Endre, G.; Saurat, O.; Dudez, A.M.; et al. Distribution of microsatellites in the genome of Medicago truncatula: A resource of genetic markers that integrate genetic and physical maps. Genetics 2006, 172, 2541-2555. [CrossRef] [PubMed]

34. Sambrook, J.; Russell, D. Molecular Cloning. A Laboratory Manual; Cold Spring Harbor Laboratory Press: Cold Spring Harbor, NY, USA, 2001.

35. Domonkos, A.; Horvath, B.; Marsh, J.F.; Halasz, G.; Ayaydin, F.; Oldroyd, G.E.D.; Kalo, P. The identification of novel loci required for appropriate nodule development in Medicago truncatula. BMC Plant Biol. 2013, 13, 157. [CrossRef] [PubMed]

36. Montiel, J.; Downie, J.A.; Farkas, A.; Bihari, P.; Herczeg, R.; Balint, B.; Mergaert, P.; Kereszt, A.; Kondorosi, E. Morphotype of bacteroids in different legumes correlates with the number and type of symbiotic NCR peptides. Proc. Natl. Acad. Sci. USA 2017, 114, 5041-5046. [CrossRef] [PubMed]

37. Kakar, K.; Wandrey, M.; Czechowski, T.; Gaertner, T.; Scheible, W.; Stitt, M.; Torres-Jerez, I.; Xiao, Y.; Redman, J.; Wu, H.; et al. A community resource for high-throughput quantitative RT-PCR analysis of transcription factor gene expression in Medicago truncatula. Plant Methods 2008, 4, 18. [CrossRef] [PubMed]

38. Horvath, B.; Domonkos, A.; Kereszt, A.; Szucs, A.; Abraham, E.; Ayaydin, F.; Boka, K.; Chen, Y.H.; Chen, R.J.; Murray, J.D.; et al. Loss of the nodule-specific cysteine rich peptide, NCR169, abolishes symbiotic nitrogen fixation in the Medicago truncatula dnf7 mutant. Proc. Natl. Acad. Sci. USA 2015, 112, 15232-15237. [CrossRef] [PubMed]

39. Boisson-Dernier, A.; Chabaud, M.; Garcia, F.; Becard, G.; Rosenberg, C.; Barker, D. Agrobacterium rhizogenestransformed roots of Medicago truncatula for the study of nitrogen-fixing and endomycorrhizal symbiotic associations. Mol. Plant Microbe Interact. 2001, 14, 695-700. [CrossRef] [PubMed]

40. Smit, P.; Raedts, J.; Portyanko, V.; Debelle, F.; Gough, C.; Bisseling, T.; Geurts, R. NSP1 of the GRAS protein family is essential for rhizobial nod factor-induced transcription. Science 2005, 308, 1789-1791. [CrossRef] [PubMed]

41. Curtis, M.D.; Grossniklaus, U. A gateway cloning vector set for high-throughput functional analysis of genes in planta. Plant Physiol. 2003, 133, 462-469. [CrossRef] [PubMed]

42. Maniatis, T.; Fritsch, E.; Sambrook, J. Molecular Cloning: A Laboratory Manual; Cold Spring Laboratory Press: Cold Spring Harbor, NY, USA, 1982.

43. Iantcheva, A.; Chabaud, M.; Cosson, V.; Barascud, M.; Schutz, B.; Primard-Brisset, C.; Durand, P.; Barker, D.; Vlahova, M.; Ratet, P. Osmotic shock improves Tnt1 transposition frequency in Medicago truncatula cv jemalong during in vitro regeneration. Plant Cell Rep. 2009, 28, 1563-1572. [CrossRef] [PubMed]

44. Tadege, M.; Wen, J.Q.; He, J.; Tu, H.D.; Kwak, Y.; Eschstruth, A.; Cayrel, A.; Endre, G.; Zhao, P.X.; Chabaud, M.; et al. Large-scale insertional mutagenesis using the Tnt1 retrotransposon in the model legume Medicago truncatula. Plant J. 2008, 54, 335-347. [CrossRef] [PubMed]

45. Starker, C.G.; Parra-Colmenares, A.L.; Smith, L.; Mitra, R.M.; Long, S.R. Nitrogen fixation mutants of Medicago truncatula fail to support plant and bacterial symbiotic gene expression. Plant Physiol. 2006, 140, 671-680. [CrossRef] [PubMed]

46. Tang, H.B.; Krishnakumar, V.; Bidwell, S.; Rosen, B.; Chan, A.N.; Zhou, S.G.; Gentzbittel, L.; Childs, K.L.; Yandell, M.; Gundlach, H.; et al. An improved genome release (version Mt4.0) for the model legume Medicago truncatula. BMC Genom. 2014, 15, 312. [CrossRef] [PubMed]

47. Roux, B.; Rodde, N.; Jardinaud, M.F.; Timmers, T.; Sauviac, L.; Cottret, L.; Carrere, S.; Sallet, E.; Courcelle, E.; Moreau, S.; et al. An integrated analysis of plant and bacterial gene expression in symbiotic root nodules using laser-capture microdissection coupled to RNA sequencing. Plant J. 2014, 77, 817-837. [CrossRef] [PubMed]

48. Nelson, B.K.; Cai, X.; Nebenfuhr, A. A multicolored set of in vivo organelle markers for co-localization studies in Arabidopsis and other plants. Plant J. 2007, 51, 1126-1136. [CrossRef] [PubMed]

49. Wang, R.W.; Brattain, M.G. The maximal size of protein to diffuse through the nuclear pore is larger than 60 kDa. FEBS Lett. 2007, 581, 3164-3170. [CrossRef] [PubMed]

50. Schwarz, D.S.; Blower, M.D. The endoplasmic reticulum: Structure, function and response to cellular signaling. Cell. Mol. Life Sci. 2016, 73, 79-94. [CrossRef] [PubMed]

51. Eichmann, R.; Schafer, P. The endoplasmic reticulum in plant immunity and cell death. Front. Plant Sci. 2012, 3, 200. [CrossRef] [PubMed] 
52. Haynes, J.; Czymmek, K.; Carlson, C.; Veereshlingam, H.; Dickstein, R.; Sherrier, D. Rapid analysis of legume root nodule development using confocal microscopy. New Phytol. 2004, 163, 661-668. [CrossRef]

53. Nicholson, R.L.; Hammerschmidt, R. Phenolic compounds and their role in disease resistance. Annu. Rev. Phytopathol. 1992, 30, 369-389. [CrossRef]

54. Terpolilli, J.; O'Hara, G.; Tiwari, R.; Dilworth, M.; Howieson, J. The model legume Medicago truncatula A17 is poorly matched for $\mathrm{N}_{2}$ fixation with the sequenced microsymbiont Sinorhizobium meliloti 1021. New Phytol. 2008, 179, 62-66. [CrossRef] [PubMed]

55. Leigh, J.A.; Signer, E.R.; Walker, G.C. Exopolysaccharide-deficient mutants of Rhizobium meliloti that form ineffective nodules. Proc. Natl. Acad. Sci. USA 1985, 82, 6231-6235. [CrossRef] [PubMed]

56. Karunakaran, R.; Haag, A.F.; East, A.K.; Ramachandran, V.K.; Prell, J.; James, E.K.; Scocchi, M.; Ferguson, G.P.; Poole, P.S. BacA is essential for bacteroid development in nodules of galegoid, but not phaseoloid, legumes. J. Bacteriol. 2010, 192, 2920-2928. [CrossRef] [PubMed]

57. Glazebrook, J.; Ichige, A.; Walker, G.C. A Rhizobium meliloti homolog of the Escherichia coli peptide-antibiotic transport protein SbmA is essential for bacteroid development. Genes Dev. 1993, 7, 1485-1497. [CrossRef] [PubMed]

58. Debelle, F.; Plazanet, C.; Roche, P.; Pujol, C.; Savagnac, A.; Rosenberg, C.; Prome, J.C.; Denarie, J. The NodA proteins of Rhizobium meliloti and Rhizobium tropici specify the $N$-acylation of Nod factors by different fatty acids. Mol. Microbiol. 1996, 22, 303-314. [CrossRef] [PubMed]

59. Kiss, E.; Olah, B.; Kalo, P.; Morales, M.; Heckmann, A.; Borbola, A.; Lozsa, A.; Kontar, K.; Middleton, P.; Downie, J.; et al. LIN, a novel type of U-Box/WD40 protein, controls early infection by rhizobia in legumes. Plant Physiol. 2009, 151, 1239-1249. [CrossRef] [PubMed]

60. Horvath, B.; Yeun, L.H.; Domonkos, A.; Halasz, G.; Gobbato, E.; Ayaydin, F.; Miro, K.; Hirsch, S.; Sun, J.H.; Tadege, M.; et al. Medicago truncatula IPD3 is a member of the common symbiotic signaling pathway required for rhizobial and mycorrhizal symbioses. Mol. Plant Microbe Interact. 2011, 24, 1345-1358. [CrossRef] [PubMed]

61. Gourion, B.; Berrabah, F.; Ratet, P.; Stacey, G. Rhizobium-legume symbioses: The crucial role of plant immunity. Trends Plant Sci. 2015, 20, 186-194. [CrossRef] [PubMed]

62. Zipfel, C.; Oldroyd, G.E.D. Plant signalling in symbiosis and immunity. Nature 2017, 543, 328-336. [CrossRef] [PubMed] 